\title{
Preventive action of benztropine on platinum-induced peripheral neuropathies and tumor growth
}

Olivier Cerles' ${ }^{1}$ Tânia Cristina Gonçalves ${ }^{2,3}$, Sandrine Chouzenoux ${ }^{1}$ Evelyne Benoit ${ }^{2}$, Alain Schmitt ${ }^{4}$, Nathaniel Edward Bennett Saidu ${ }^{1}$, Niloufar Kavian ${ }^{1,5}$, Christiane Chéreau ${ }^{1}$, Camille Gobeaux ${ }^{6}$, Bernard Weill ${ }^{1,5}$, Romain Coriat ${ }^{1,7}$, Carole Nicco ${ }^{1+}$ (D) and Frédéric Batteux ${ }^{1,5^{*}+}$

\begin{abstract}
The endogenous cholinergic system plays a key role in neuronal cells, by suppressing neurite outgrowth and myelination and, in some cancer cells, favoring tumor growth. Platinum compounds are widely used as part of first line conventional cancer chemotherapy; their efficacy is however limited by peripheral neuropathy as a major side-effect. In a multiple sclerosis mouse model, benztropine, that also acts as an anti-histamine and a dopamine re-uptake inhibitor, induced the differentiation of oligodendrocytes through M1 and M3 muscarinic receptors and enhanced re-myelination. We have evaluated whether benztropine can increase anti-tumoral efficacy of oxaliplatin, while preventing its neurotoxicity.

We showed that benztropine improves acute and chronic clinical symptoms of oxaliplatin-induced peripheral neuropathies in mice. Sensory alterations detected by electrophysiology in oxaliplatin-treated mice were consistent with a decreased nerve conduction velocity and membrane hyperexcitability due to alterations in the density and/or functioning of both sodium and potassium channels, confirmed by action potential analysis from ex-vivo cultures of mouse dorsal root ganglion sensory neurons using whole-cell patch-clamp. These alterations were all prevented by benztropine. In oxaliplatin-treated mice, MBP expression, confocal and electronic microscopy of the sciatic nerves revealed a demyelination and confirmed the alteration of the myelinated axons morphology when compared to animals injected with oxaliplatin plus benztropine. Benztropine also prevented the decrease in neuronal density in the paws of mice injected with oxaliplatin. The neuroprotection conferred by benztropine against chemotherapeutic drugs was associated with a lower expression of inflammatory cytokines and extended to diabetic-induced peripheral neuropathy in mice.

Mice receiving benztropine alone presented a lower tumor growth when compared to untreated animals and synergized the anti-tumoral effect of oxaliplatin, a phenomenon explained at least in part by benztropine-induced ROS imbalance in tumor cells.

This report shows that blocking muscarinic receptors with benztropine prevents peripheral neuropathies and increases the therapeutic index of oxaliplatin. These results can be rapidly transposable to patients as benztropine is currently indicated in Parkinson's disease in the United States.
\end{abstract}

Keywords: Benztropine, Oxaliplatin, Peripheral neuropathies, Muscarinic receptors, Myelin

\footnotetext{
* Correspondence: frederic.batteux@cch.aphp.fr

${ }^{\dagger}$ Carole Nicco and Frédéric Batteux contributed equally to this work.

'Department "Development, Reproduction and Cancer", Institut Cochin, Paris

Descartes University, Sorbonne Paris City, INSERM U1016, Paris, France

${ }^{5}$ Department of Immunology, Cochin Teaching Hospital, AP-HP, 27, rue du

faubourg Saint-Jacques, F75014 Paris, France

Full list of author information is available at the end of the article
}

(c) The Author(s). 2019 Open Access This article is distributed under the terms of the Creative Commons Attribution 4.0 International License (http://creativecommons.org/licenses/by/4.0/), which permits unrestricted use, distribution, and reproduction in any medium, provided you give appropriate credit to the original author(s) and the source, provide a link to the Creative Commons license, and indicate if changes were made. The Creative Commons Public Domain Dedication waiver (http://creativecommons.org/publicdomain/zero/1.0/) applies to the data made available in this article, unless otherwise stated. 


\section{Introduction}

Chemotherapy-induced peripheral neuropathy (CIPN) is a severe and long lasting side effect caused by diverse anticancer agents that damage sensory and/or motor nerves. CIPN occurs in 30-70\% of patients treated with specific categories of anticancer agents [72]. Symptoms of CIPN include numbness, pain, burning, tingling, heat/ cold hyperalgesia, and mechanical allodynia, as well as reduced motor function. CIPN commonly presents a "stocking-glove" distribution with the most distal portions of the limb exhibiting the greatest deficits [9]. These symptoms usually begin after multiple doses of the chemotherapeutic agents, and progress as treatment continues. After the treatments end, they can resolve in a short time period, or persist as an after-effect of cancer therapy.

Oxaliplatin-associated CIPN is the most frequent cause of interruption of an otherwise successful therapy [34]. About 12 to $18 \%$ of patients experience the highest grade 3 CIPN evaluated on the National Cancer Institute's Common Terminology Criteria for Adverse Events (NCI-CTCAE) scale [4, 21], when persistent neuropathy graded more than 2 usually results in complete discontinuation of the chemotherapy.

Oxaliplatin is a platinum compound indicated in solid tumor cancers $[38,87]$, which induces peripheral neuropathies of two forms: an acute but reversible form [54] which manifests within hours following the first infusion and a chronic form that occurs following cumulative high doses of the drug and is non-reversible [66]. Several clinical manifestations characterize this condition, but hallmark symptoms include persistent distal chronic paresthesia, allodynia and thermoalgesia. Indeed, the severity of the pain endured by some patients may require treatment arrest, rendering this neuropathy a limiting-factor for this chemotherapy.

The mechanisms behind the neurotoxicity of chemotherapy are complex and are not fully understood $[6,15]$. Neurotoxicity may be due to chemotherapy interactions with DNA, mitochondrial perturbations, ion channel dysregulations, reactive oxygen balance modifications, kinases and/or glutamatergic neurotransmission dysfunction. The lesions can occur at the level of the dorsal root ganglia (DRG), at the level of the sensory neurons, associated with defects of axonal transport related to the microtubules or to degeneration of the axon. They may also affect Schwann cells by inducing dedifferentiation and mitochondrial [37] and satellite cell [13] dysfunction. The complexity of the involved mechanisms partly explains the lack of effective treatments to prevent CIPN.

Diabetic neuropathies (DN) are similar in their anatomo-pathological features to oxaliplatin-induced peripheral neuropathies, as they involve demyelination, axonal swelling and reduced cutaneous nerve fiber density $[36,74]$. A progressive development with sensory loss, pain and autonomic dysfunction are common symptoms. Pathologically, DN is characterized by interrelated metabolic abnormalities with insulin deficiency and hyperglycemia as the initiating culprits. The neuropathy accompanying type 2 DM (insulin resistance) and type $1 \mathrm{DM}$ (insulin deficiency) appears to differ, the former showing a milder axonal involvement and segmental myelin breakdown, whereas the latter shows a more severe axonal atrophy and axonal loss. The disorder does not only involve somatic peripheral nerves but also autonomic and central nerve tracts. Today no successful therapy exists for DN.

In both CIPN [13] and DN [25], myelin-forming Schwann cells of the peripheral nervous system are crucial for the proper function and maintenance of peripheral nerves. Schwann cells wrap around axons and thereby provide insulation, acceleration of electric signal propagation, and axonal protection and maintenance. Schwann cells are the main effectors for regeneration in a variety of peripheral neuropathic conditions [31, 32, 51], including inherited, inflammatory, toxic (e.g. CIPN), and DN, as well as traumatic injuries to peripheral nerve fibers. Due to their high differentiation plasticity, these cells respond to injury and disease by myelin sheath degradation, dedifferentiation into an immature Schwann cell-like phenotype. In doing so, they can support and promote axonal regrowth and target tissue innervation.

Based on our current knowledge, it is evident that Schwann cells play a key role in the pathogenesis of various inflammatory, metabolic and hereditary polyneuropathies [31, 51]. Over the last two decades, fundamental progress has been made in understanding the molecular basis of Schwann cell biology. These advances have led to the development of new treatment strategies that aim to improve the protective and regenerative properties of Schwann cells in peripheral nerve disorders. The neuroprotective potential of a molecule which improves clinical symptoms of experimental autoimmune encephalomyelitis in mice by remyelinating neurons has recently been reported [22]. Benztropine, an inhibitor of acetylcholine (ACh) muscarinic $\mathrm{M} 1$ and $\mathrm{M} 3$ receptors (mAChR), has been shown to promote oligodendrocyte precursor cells differentiation while allowing greater axonal remyelination than molecules currently prescribed to multiple sclerosis patients [22]. Interestingly, M3 and M1 mAChR are also expressed on peripheral myelin forming Schwann cells but their roles in the myelination process remain unclear. In a multiple sclerosis mouse model, benztropine induced the differentiation of oligodendrocytes through M1 and M3 muscarinic receptors and enhanced re-myelination [22]. In addition to its anti-cholinergic effects, benztropine also produces anti-histaminic effects [58], inhibits the re-uptake of terminal nerve dopamine [2] and is an allosteric antagonist of the human D2 dopamine receptor 
(Pubchem BioAssay: AID 485344 and Drugbank.ca: DB00245).

However, targeting a pathway to prevent CIPN must be considered with caution, since this additional treatments may directly or indirectly favor tumor growth or dissemination. Interestingly, in the case of muscarinic receptor blockade, several studies have highlighted the potential of targeting M3 muscarinic receptors to prevent tumor growth and metastases [17, 19, 77]. Furthermore, ACh-induced tumorigenesis has been reported in several organs that are commonly treated with oxaliplatin [17, 91]. The differential distribution between mAChR subtypes could allow the specific targeting of tumor cells.

These observations of potential for both preventing neurotoxicity by promoting axonal protection as well as increasing the efficacy profile of neurotoxic chemotherapies, prompted us to investigate the effects of the mAChR inhibitor, benztropine, associated with oxaliplatin, in vitro and in vivo on CIPN, DN and tumor growth.

\section{Materials and methods}

\section{Cell culture and treatments}

CT26 (mouse colon carcinoma) cells, purchased from the ATCC (CRL-2638), were grown in Dulbecco's Modified Eagle Medium (Gibco, Sigma-Aldrich) with 10\% FBS (Gibco, Sigma-Aldrich), penicillin/streptomycin, and L-glutamine supplementation. N2a (mouse brain neuroblastoma) cells, purchased from the ATCC (CCL-131), were grown in Eagle Minimum Essential Medium supplemented with $10 \%$ FBS, penicillin/streptomycin, $2 \%$ sodium pyruvate, $1 \%$ ciprofloxacin, non-essential amino acids, and L-glutamine supplementation.

\section{Animal models and treatments}

Five-week-old male BALB/cJRj mice were purchased from Janvier Laboratory (Le Genest Saint Isle, France). All mice were housed in ventilated cages $(n=7$ to 10 animals per cage) with sterile food and water ad libitum and were exposed to a standard light cycle of $12 \mathrm{~h}$ on and $12 \mathrm{~h}$ off. All experiments were performed in accordance with European and French institutional guidelines (Directive 2010/63/EU, Ethics committee CEEA 34 APAFIS authorization \#8394).

\section{Model of oxaliplatin-induced peripheral neuropathies}

Both models of oxaliplatin-induced peripheral neuropathies, namely, the acute form and the chronic form were induced by protocols with timeframes that were analogous to the clinical protocols which results in the induction of either of these forms in patients, and were previously used in mice.
The acute form of oxaliplatin peripheral neuropathy was induced in mice ( $n=7$ per group) by daily low doses intraperitoneal injections of oxaliplatin $(3 \mathrm{mg} / \mathrm{kg}$ diluted in phosphate-buffered saline (PBS 1X)) for 5 days followed by 5 days of rest and another 5 days of oxaliplatin at the same dosage, as previously described $[16,18$, 79]. Benztropine (10 mg/ $\mathrm{kg}$ diluted in PBS) was administered as daily intraperitoneal injections $6 \mathrm{~h}$ after oxaliplatin injection, 5 days a week during the 2 cycles of oxaliplatin injection and the rest period.

The chronic form of oxaliplatin peripheral neuropathy mice ( $n=25$ per group for all the experiments) was induced by intraperitoneal injections of oxaliplatin $(10 \mathrm{mg} /$ $\mathrm{kg}$ diluted in PBS) once a week each Mondays for 6-8 weeks as previously described [16, 18, 89]. Benztropine (10 mg/kg diluted in PBS) was administered as daily intraperitoneal injections $6 \mathrm{~h}$ after oxaliplatin injection, 5 days a week for $6-8$ weeks.

\section{Model of streptozotocin-induced diabetic peripheral neuropathies}

Poor survival over the course of preliminary tests was observed with a 3-h food withdrawal before and after a single dose of $200 \mathrm{mg} / \mathrm{kg}$ of Streptozotocin (STZ) [39]. This dose was therefore lowered to $180 \mathrm{mg} / \mathrm{kg}$ (dissolved in $10 \mathrm{mmol} / \mathrm{L}$ sodium citrate buffer, $\mathrm{pH} 4.5$ ) with 3 -h food fasting before and after the injection $(n=8$ per group). STZ was diluted to allow a final volume of 0.1 $\mathrm{ml} / 10 \mathrm{~g}$ body weight for intraperitoneal injections. One week after STZ injection, diabetes was confirmed by blood glucose levels using a Cobas 8000 modular analyzer (Roche) in blood samples taken under isoflurane 2,5\% (Isovet, \#ISO005, Centravet, Plancoët, France) from mice retro-orbital sinus. Mice with blood glucose levels $\geq 12 \mathrm{mM}$ were considered diabetic and included in the study [81].

\section{Behavioral studies}

Prior to baseline measurements for every behavioral test, mice underwent 2 weeks of acclimation sessions with the specific training protocols to familiarize them with the experimental environments and testing procedures, without probing with plastic fibers nor temperature setting. Before each behavioral test, mice were allowed to acclimate to the experimental room for $10 \mathrm{~min}$ in their home cages. Mice were only tested once on any given test day to avoid any possible stress, anesthetic or tissue damage effects that could result from repeated exposure to the cold surface.

\section{In vivo cold hyperalgesia}

Mice from the acute model of oxaliplatin-induced peripheral neuropathies were submitted to weekly tests for cold hyperalgesia. Mice were put on a cold/hot plate 
(Ugo Basile, Comerio, Italy) set at the temperature of $2^{\circ}$ $\mathrm{C} \pm 0.2^{\circ} \mathrm{C}[16,18,79]$. The total number of brisk lifts from either hind paw or jumps, considered as a painful response to cold, was counted simultaneously by two observers to ensure accuracy and averaged for the two observers' counts. A maximal cut-off time of 5 min was imposed to prevent tissue damage. Results are expressed as the mean \pm SEM of the observers' counts, with 7 different mice under each condition.

\section{In vivo cold hypoesthesia}

Mice from the chronic model of oxaliplatin-induced peripheral neuropathies were submitted to weekly tests for cold hypoesthesia which was evaluated using temperature settings previously described $[16,18]$. Briefly, mice were put on the cold/hot plate set at $4{ }^{\circ} \mathrm{C} \pm$ $0.2^{\circ} \mathrm{C}$ for $5 \mathrm{~min}$. Similar, to the test assessing cold hyperalgesia, the total number of brisk lifts from either hind paw or jumps was counted simultaneously by two observers to ensure accuracy and averaged for the two observers' counts. Results are expressed as the mean \pm SEM of the observers' counts, with 8 different mice under each condition.

\section{In vivo tactile hypoesthesia}

Mice from both the chronic oxaliplatin-induced and the diabetic models underwent weekly tests for mechanical allodynia with the von Frey method [53], a standardized protocol assessing tactile sensitivity [61]. A set of 20 monofilaments based on the Semmes Weinstein monofilament set was used (Model: Bio-VF-M, Bioseb, USA/ Canada). The Semmes Weinstein set of monofilaments provides an approximate logarithmic scale of actual force, and a linear scale of perceived intensity. Briefly, mice were put on a mesh grid, an enclosed by a clear plexiglass barrier with a top cover and left to calm down for $5 \mathrm{~min}$. After the settling phase, mice are motionless allowing the experimenter to touch their hind paws with a flexible plastic fiber of a fixed diameter. The fiber is pressed through the mesh against the plantar surface at a right angle. The force of application increases as long as the investigator pushes the probe and until the fiber bends. The scale of force used ranged from 0.008 to $1.400 \mathrm{~g}$. The threshold to perception of probing was asserted to the movement of pulling back of either hind paw of 8 different mice under each condition.

\section{In vivo hot hyperesthesia}

Mice from the diabetic model of peripheral neuropathies underwent a weekly assessment of thermal hyperalgesia according to a previously published study protocol [81]. The same equipment as for cold sensitivity was used for this experiment. The plate was set at $55^{\circ} \mathrm{C} \pm 0.2^{\circ} \mathrm{C}$. Latency to hind paw licking or jumping was recorded simultaneously by two observers with a timer and time to response was averaged for the two counts, for 8 different mice under each condition. To prevent tissue damage a cutoff time of $30 \mathrm{~s}$ was implemented.

\section{In vivo electrophysiological exploration of neuromuscular and sensory excitability}

The sensory and/or neuromuscular excitability was assessed in vivo on mice under isoflurane (AErrane $e^{\circ}$ anesthesia by minimally invasive electrophysiological methods using the Qtrac@ software (Prof. H. Bostock, Institute of Neurology, London, England), as previously described [16]. Briefly, an anaesthetized mouse $(n=10)$ was placed on a heating pad to maintain body temperature (from $36.02 \pm 0.06$ to $36.13 \pm 0.04, n=85$ ) throughout the experiments to avoid non-specific modifications of excitability variables.

For neuromuscular excitability exploration, electrical stimulation was delivered to the sciatic motor nerve by means of surface electrodes, and the compound muscle action potential (CMAP) was recorded using needle electrodes inserted into the plantar muscle. Each mouse was systematically submitted to one session of excitability measurements (TRONDE protocol), which consisted of five different excitability tests performed together: (C0) The stimulus-response relationship (i.e. the CMAP amplitude as a function of the intensity of a 1-ms stimulation) evaluated notably both the CMAP maximal amplitude and the stimulation intensity that had to be applied to evoke a CMAP of 50\% maximal amplitude, giving information on the global neuromuscular excitability state. (C1) The current-threshold relationship evaluated the threshold changes at the end of 200-ms conditioning subthreshold depolarizing and hyperpolarizing currents ranging from 50 to $100 \%$ thresholds, giving information on axonal accommodation capacities to depolarizations and hyperpolarizations. (C2) The strength-duration relationship (i.e., the intensity in relation to the duration of a stimulus necessary to evoke a given amplitude of CMAP) evaluated the minimal intensity of infinitely long duration stimulation necessary to evoke a CMAP (rheobase) and the intensity duration of twice the rheobase stimulation necessary to evoke a CMAP (chronaxis), giving information on the axonal resting potential at the nodal membrane. (C3) The threshold electrotonus (i.e., the threshold changes during and after 100-ms conditioning subthreshold depolarizing and hyperpolarizing currents applied at $\pm 40 \%$ thresholds) evaluated the electrotonic changes in membrane potential, giving also information on axonal accommodation capacities to depolarizations and hyperpolarizations. (C4) The recovery cycle (i.e., the excitability changes that occur following a CMAP) evaluated the refractory periods (during which membrane excitability is 
either nil or markedly decreased) followed by the supernormal and late subnormal periods (during which membrane excitability is increased and decreased, respectively). As a whole, more than 30 variables were determined from these excitability tests and analyzed. Most of them provide specific and complementary information on the density and functional state of ion channels, receptors and pumps, as well as on the passive membrane properties of the neuromuscular system $[45,46]$.

For sensory excitability exploration, the compound nerve action potential (CNAP) was recorded using needle electrodes inserted into the base of the tail, in response to stimulation of the caudal nerve applied at the distal part of the tail by means of surface electrodes. Each mouse was systematically and only submitted to the first session of excitability measurements (TRONDE protocol) to establish the stimulus-response relationship (i.e., the CNAP amplitude as a function of the intensity of a 1-ms stimulation) and thus, evaluate notably the CNAP maximal amplitude, the stimulation intensity that had to be applied to evoke a CNAP of 50\% maximal amplitude and the latency measured from stimulation onset to peak amplitude, giving information on the global sensory excitability state.

\section{In vitro electrophysiological exploration of sensory excitability}

In vitro electrophysiological exploration of sensory excitability was performed by recording the action potential from primary cultures of mouse dorsal root ganglia (DRG) sensory neurons, using the patch-clamp technique. After being removed from the spinal cord of euthanized adult female Swiss mice (10-12 weeks of age and $28-32 \mathrm{~g}$ body weight, purchased from Janvier Elevage and housed at the CEA animal facility), DRG were placed in iced-Ham's F-12 medium (Sigma-Aldrich, Saint-Quentin Fallavier, France) and enzymatically dissociated with collagenase type IA (2 $\mathrm{mg} / \mathrm{mL}$; Sigma-Aldrich) and dispase $(5 \mathrm{mg} / \mathrm{mL}$; Gibco, Thermo Fisher Scientific, Villebon-sur-Yvette, France). Neurons were then plated on 12-mm glass coverslips placed in a 24-wells plate coated with $10 \mu \mathrm{g} / \mathrm{mL}$ of poly-D-lysine and $100 \mu \mathrm{g} / \mathrm{mL}$ of murin laminin (Sigma-Aldrich). The cells were maintained in culture at $37^{\circ} \mathrm{C}$ (in 95\% air and $5 \% \mathrm{CO}_{2}$ ) in Neurobasal A medium (Gibco) containing horse serum (5\%; Gibco), penicillin/streptomycin (47.64 U/mL; Gibco), nerve growth factor (83.33 ng/ $\mathrm{mL}$; Sigma-Aldrich), N2 supplement (3.18x; Gibco), Dulbecco's PBS (1X) w/o $\mathrm{CaCl}_{2}$ and $\mathrm{MgCl}_{2}$ (1.68\%; Gibco), bovine serum albumin $(16.83 \mu \mathrm{g} / \mathrm{mL}$; Sigma-Aldrich), corticosteron (214.85 nM; Sigma-Aldrich), T3 hormone (56.06 $\mathrm{nM}$; Sigma-Aldrich) and L-glutamine $(1.90 \mathrm{mM}$; Sigma-Aldrich). Cytosine $\beta$-D-arabinofuranoside $(2 \mu \mathrm{M}$; Sigma-Aldrich) was added to the culture medium, $24 \mathrm{~h}$ later, to stop astrocyte proliferation. Experiments were carried out within 2 to 6 days after cell plating. The day of their use, the neurons plated on coverslips were transferred, for a minimum of $30 \mathrm{~min}$ at $37^{\circ} \mathrm{C}$ prior to patch-clamp recordings, in 35- $\mathrm{mm}$ Petri dishes filled with a standard physiological medium of the following composition (in $\mathrm{mM}$ ): $\mathrm{NaCl} 134, \mathrm{KCl} 3, \mathrm{CaCl}_{2} 1, \mathrm{MgCl}_{2} 1$, D-glucose 20, and HEPES 20 (pH 7.35, adjusted with $\mathrm{NaOH}$ ), and then in the recording bath filled with the standard physiological medium.

Whole-cell patch-clamp experiments were performed under current-clamp condition, by using a MultiClamp 700B integrating patch-clamp amplifier and the pClamp10.6 software (Molecular Devices, Sunnyvale, CA, USA), as previously described [70]. The signals, acquired at a $4-\mathrm{kHz}$ sample rate, were filtered at $2 \mathrm{kHz}$ with a low-pass Bessel filter and digitized with the aid of a computer equipped with an analog-to-digital converter (Digidata-1440A model; Molecular Devices). The patch-clamp pipettes were filled with a medium composed of (in $\mathrm{mM}$ ): $\mathrm{KCl} 134, \mathrm{NaCl} 10, \mathrm{MgCl}_{2}$ 2, EGTA 2, ATP- $\mathrm{Na}_{2}$ 4, and HEPES 20 (pH 7.32, adjusted with $\mathrm{KOH})$, and had $2.71 \pm 0.25 \mathrm{M} \Omega$ resistance $(n=18)$ in the standard physiological medium. A fast superfusion system allowed changing the solution [standard physiological medium without or with oxaliplatin $(25-50 \mu \mathrm{M})$ alone or oxaliplatin $(25-50 \mu \mathrm{M})$ plus benztropine $(10 \mu \mathrm{M})]$ around the recorded cell within a few seconds. The experiments were carried out at constant room temperature $\left(22^{\circ} \mathrm{C}\right)$. Action potentials were elicited, at a frequency of $0.5 \mathrm{~Hz}$, by 100 -ms current test-pulses of 0.2 to $1 \mathrm{nA}$ (in $0.1-\mathrm{nA}$ increments) applied $200 \mathrm{~ms}$ after 200-ms current pre-pulses of $-0.1 \mathrm{nA}$ (to check the membrane passive properties of neurons, mainly membrane capacitance).

\section{Ex vivo confocal microscopy morphological study of sciatic nerves}

The experiments were carried out on single myelinated axons isolated from the sciatic nerves of euthanized mice, as previously detailed [16]. Briefly, sciatic nerve sections ( $n=4$ mice in each group) of about $2 \mathrm{~cm}$ in length were removed from their sheaths, dissected, and fixed for $1 \mathrm{~h}$ in PBS $1 \mathrm{X}$ with 2\% paraformaldehyde, then rinsed three times with PBS. Sciatic nerves were deposited on microscope slides, myelinated axons were gently teased apart from the main trunk, and preparations were kept at $-20^{\circ} \mathrm{C}$ until use. Just before the experiments, sciatic nerves were rehydrated for about $1 \mathrm{~h}$ with a standard physiological solution containing (in $\mathrm{mM}$ ): $\mathrm{NaCl} 154, \mathrm{KCl} 5, \mathrm{CaCl}_{2} 2, \mathrm{MgCl}_{2} 1$, glucose 11, and HEPES 5 (pH 7.4, adjusted with $\mathrm{NaOH}$. Preparations were then exposed for $30 \mathrm{~min}$ to the fluorescent dye FM1-43 (Molecular Probes) dissolved in a standard physiological solution to stain the plasma membranes of 
the myelinated axons, and washed with dye-free solution before imaging. A Zeiss LSM 510 META (Carl Zeiss) multiphoton scanning confocal microscope, mounted on an upright microscope and controlled with the manufacturer's software and workstation, was used for optical sectioning of myelinated axons and subsequent 3D high-resolution digital reconstruction of their structure. Images were collected using a $63 \mathrm{x}$ oil-immersion objective with a 1.40 numerical aperture (Zeiss Plan-Apochromat); following excitation of FM1-43 with the $488 \mathrm{~nm}$ wavelength line of an Argon ion laser, and then digitized at 12-bit resolution into a $512 \times 512$ pixel array. Images were then analyzed using the ImageJ software (National Institutes of Health - NIH). Quantification of morphometric parameters of myelinated axons were performed by measuring the internodal diameter, nodal diameter (D) and nodal length (L). Assuming the simplest geometry in which a node of Ranvier approaches a cylinder, the nodal volume $(\mathrm{V})$ was then determined as $\mathrm{V}=\mu \mathrm{L}(\mathrm{D} / 2)^{2}$.

\section{Ex vivo electronic microscopy morphological study of sciatic nerves}

Mice were anesthetized by intraperitoneal injections of $100 \mathrm{mg} / \mathrm{kg}$ ketamine and $10 \mathrm{mg} / \mathrm{kg}$ xylazine and then intracardially perfused with first, $0.1 \mathrm{M}$ PBS, $\mathrm{pH}$ 7.4, for 8 min and then $4 \%$ paraformaldehyde, $2.5 \%$ glutaraldehyde, and 0.1 M PBS, pH 7.4. Mice were euthanized after complete rigidity of the lower limbs and liver (endpoint of the perfusion). Tissues were dissected $24 \mathrm{~h}$ later and immersed in the fixative solution at $4{ }^{\circ} \mathrm{C}$ for $72 \mathrm{~h}$, washed in PBS, post-fixed in $2 \%$ osmium tetroxide, dehydrated in graded ethanol, and embedded in epoxy resin. Ultrathin sections $(50-90 \mathrm{~nm})$ were cut on an ultramicrotome (8800 Ultrotome III; LKB Bromma) and collected on 300-mesh nickel grids. Staining was performed on drops of $4 \%$ aqueous uranyl acetate, followed by Reynolds lead citrate. Ultrastructural analyses were performed in a JEOL JEM-1011 electron microscope and digitalized with DigitalMicrograph software. G-ratios and axon diameters mice ( $n=2$ to 3 mice in each group) were calculated with the ImageJ software (National Institutes of Health) and the plugin $g$-ratio version 3.2 (Plug-in and source code available online at http:// gratio.efil.de) according to previously published material [30]. Diameters were calculated from enclosed areas, considering first, the diameter of the axon without the myelin and dividing it by the diameter of the axon plus the myelin sheaths surrounding it. The plugin allows for semi-automated analysis of randomly selected fibers with both diameters being considered and automatically processed through the algorithm to calculate the g-ratio. A minimum of 500 randomly selected axons were analyzed per experimental group, with at least 3 mice per group.

\section{Ex vivo study of cutaneous nerve fiber density}

Sections of skin from the hind paws of 8 mice per group were preserved in buffered $4 \%$ formol (VWR Chemicals, Labonord SAS, France) and immersed in successive baths of increasing concentrations of ethanol (50, 70, 90, $100 \%)$. Samples were then immersed in histosol before being fixed in paraffin, kept at $4{ }^{\circ} \mathrm{C}$ and cut into $6 \mu \mathrm{m}$-thick slices. Samples were then unwaxed in three successive baths of histosol for $3 \mathrm{~min}$ and rehydrated in ethanol baths for 1 min each, starting with two baths of pure ethanol followed with baths of 90,70 and 30\% ethanol and two baths of $\mathrm{H}_{2} \mathrm{O}$. Slides were then washed in PBS for 2 min before being immersed in citrate buffer at $95^{\circ} \mathrm{C}$ for $10 \mathrm{~min}$. Samples were washed in 3 baths of PBS of 5 min each. Samples were then permeabilized (PBS, $0.25 \%$ Triton $\mathrm{X}-100$ ) for $10 \mathrm{~min}$ before being rinsed in PBS in 3 baths of $5 \mathrm{~min}$ each and immersed in a blocking solution (PBS, 10\% goat serum, 1\% BSA) for at least $180 \mathrm{~min}$. Samples were further incubated at $4{ }^{\circ} \mathrm{C}$ overnight in the primary antibody (Abcam, ab10404, rabbit polyclonal to PGP9.5, 1:1000) before being rinsed in PBS in 3 baths of $5 \mathrm{~min}$ each before incubating in the secondary antibody (Sigma, F9887, anti-rabbit IgG FITC-conjugate, 1:1000) at room temperature in the dark. Prior to mounting (Thermo Scientific, Shandon Immuno-Mount), slides were washed with PBS in 3 baths of $5 \mathrm{~min}$ each. Images were collected using a Nikon Eclipse 80i microscope with a Nikon PlanFluor 100x/1.30 oil-immersion DIC H/N2 objective.

\section{Ex vivo study of myelin protein content in sciatic nerves}

Nerves were extracted in lysis buffer containing a cocktail of proteinase and phosphatase inhibitors using a glass homogenizer. Protein lysate samples $(40 \mathrm{~g})$ were resolved on $10 \%$ SDS-PAGE gels and transferred by electrophoresis to nitrocellulose membranes. The membranes were blocked for non-specific binding sites at room temperature in TBS buffer containing $0.1 \%$ Tween 20 and $5 \%$ nonfat dried milk for $1 \mathrm{~h}$. The membranes were then incubated overnight at $4{ }^{\circ} \mathrm{C}$ with a primary antibody against MBP (1:500; Merck). Subsequently, the membranes were incubated with an anti-rabbit IgG, horseradish peroxidase linked whole antibody from donkey (1:1000; GE Healthcare Life Sciences NA934, Little Chalfont, UK) and subjected to ECL reagent treatment. After film exposure, all membranes were washed and then incubated with a 1:50,000 dilution of mouse monoclonal anti-actin-peroxidase antibody (Sigma Aldrich; Saint Louis, Missouri, USA) as previously described [52].The images were captured using a CCD camera (LAS3000 from Fujifilm), and the bands were quantified using MultiGauge software from Fujifilm. 


\section{Ex vivo study of systemic inflammatory markers}

Blood samples were taken under isoflurane from the retro-orbital sinus immediately before sacrifice $(n=8$ per group), centrifuged at $10.000 \mathrm{rpm}$ and $2{ }^{\circ} \mathrm{C}$. Sera were diluted (1:4) in ELISA/ELISPOT diluent $1 \mathrm{X}$ before being distributed on ELISA 96-well plates specific of IL-6 and Tumor necrosis factor alpha (TNF- $\alpha$; Mouse IL-6 ELISA Ready-SET-Go! ${ }^{\circ}$ and Mouse TNF ELISA Ready-SET-Go! ${ }^{\circ}$ - eBioscience, San Diego, CA, USA). Concentrations were calculated from a standard curve according to the manufacturer's protocol.

\section{In vivo study of antitumor activity of benztropine upon association with chemotherapy}

A total of $1.10^{6}$ viable CT26 cells, as determined by trypan blue staining, and resuspended in DMEM were injected subcutaneously into the back of the mice. When tumors reached a mean size of 200 to $500 \mathrm{~mm}^{3}$, animals were randomized and received a single weekly injection of either oxaliplatin $(10 \mathrm{mg} / \mathrm{kg})$ or vehicle. Concomitantly, mice received vehicle or benztropine $(10 \mathrm{mg} / \mathrm{kg})$ every day. Following randomization, tumor size was measured with a numeric caliper twice a week for 3 weeks. In order to comply with ethical guidelines, tumor growth experiments were stopped 3 weeks after the first oxaliplatin injection. Tumor volume was calculated as follows: $T V\left(\mathrm{~mm}^{3}\right)=\left(L \times W^{2}\right) / 2$, where $L$ is the longest and $W$ the shortest radius of the tumor in millimeters. Results are expressed as mean \pm SD of tumor volumes ( $n=7$ in each group).

\section{Viability and ROS assays}

All cells $\left(2 \times 10^{4}\right.$ per well) were seeded in 96-well plates (Sigma-Aldrich, Saint-Quentin Fallavier France) and incubated for $24 \mathrm{~h}$ with 7.5 to $30 \mu \mathrm{M}$ of benztropine (Sigma-Aldrich, Saint-Quentin Fallavier France) and treated with 0 to $100 \mu \mathrm{M}$ of oxaliplatin (Accord Healthcare Limited, Lille, France). Cell viability was assessed by a crystal violet assay, and results are expressed as the mean percentage of viable cells \pm SEM versus cells not exposed to oxaliplatin ( $100 \%$ viability). Cellular production of ROS and reduced glutathione (GSH) were assessed by spectrofluorimetry with $2^{\prime}, 7^{\prime}$-dichlorodihydrofluorescein diacetate (H2DCFDA, \#6883 Sigma-Aldrich, Saint-Quentin Fallavier France) and monochlorobimane (\#69899 Sigma-Aldrich), respectively [49].

\section{Statistical analysis}

Statistical analysis was performed using GraphPad Prism 5. Artwork, was also created using GraphPad Prism 5, except for electrophysiological study artwork which was created using the Qtrac $\odot$ software. Differences between values were tested using the unpaired Student's $t$-test, two-way ANOVA, or the nonparametric Mann-Whitney
$U$ test, depending on the equality of variances estimated using Lilliefors test. They were considered significant when $p<0.05, p$ values being denoted as follows: " $p<0.05$, "** $p<0.01,{ }^{* * * * *} p<0.001,{ }^{* * * * *} p<0.0001$; NS: non-significant.

\section{Results}

In vivo effects of oxaliplatin and benztropine on mouse cold hyperalgesia

To determine whether benztropine could abrogate oxaliplatin-induced peripheral neuropathy, cold hyperalgesia was evaluated in acute oxaliplatin-exposed mice treated or not with benztropine. After oxaliplatin cycle 1 , the mean number of brisk lifts was over twice as high in oxaliplatin-treated mice than in animals injected with vehicle alone $(26.57 \pm 2.45$ with oxaliplatin versus 11.43 \pm 1.13 with vehicle, $p=0.0001$ ). The same changes were observed after the second injection of oxaliplatin (17.43 \pm 1.70 with oxaliplatin versus $11.29 \pm 0.84$ with vehicle, $p=0.0071$ ). Association with benztropine rescued this hyperalgesia from the first injection of oxaliplatin (17.71 \pm 2.76 with oxaliplatin plus benztropine versus $11.43 \pm$ 1.13 with vehicle, $p=0.0566$ ) (Fig. 1).

\section{In vivo effects of oxaliplatin and benztropine on mouse cold and tactile hypoesthesia}

In addition to acute cold hyperalgesia, after a long term treatment, patients treated with oxaliplatin also suffer from permanent pathological thermal and tactile perception at their extremities. Submitted to the chronic form oxaliplatin-induced peripheral neuropathy, mice injected with $10 \mathrm{mg} / \mathrm{kg}$ oxaliplatin developed diminished tactile perception from week 3 of treatment $(0.2419 \pm 0.0687$ with oxaliplatin versus $0.0625 \pm 0.0107$ with vehicle, $p=$ 0.0151 ) with a peak tactile hypoesthesia observed at the end of the testing period (at week 6, $0.7225 \pm 0.0973$ with oxaliplatin versus $0.1188 \pm 0.0348$ with vehicle, $p<$ $0.0001)$. Mice treated with benztropine associated with the chemotherapy did not display these symptoms of altered tactile hypoesthesia at week $3(0.1515 \pm 0.0704$ with oxaliplatin plus benztropine versus $0.0625 \pm 0.0107$ with vehicle, $p=0.2212$ ) nor at any time point during the experiment (at week $6,0.1575 \pm 0.0458$ with oxaliplatin plus benztropine versus $0.1188 \pm 0.0348$ with vehicle, $p=0.5054$ ) (Fig. 2a). Mice injected with $10 \mathrm{mg} / \mathrm{kg}$ oxaliplatin developed reduced cold hypoesthesia from week 3 of treatment $(13.13 \pm 1.11$ with oxaliplatin versus $17.25 \pm 0.87$ with vehicle, $p=0.0066$ ). The most severe cold hypoesthesia in oxaliplatin-treated mice was observed at the end of the testing period (at week 6, $5.44 \pm 0.36$ with oxaliplatin versus $16.19 \pm 0.81$ with vehicle, $p<0.0001)$. Mice treated with benztropine associated with the chemotherapy did not display these symptoms of altered cold hypoesthesia at week 3 $(15.56 \pm 1.00$ with oxaliplatin plus benztropine versus 


\section{Cold hyperalgesia}

$\left(2^{\circ} \mathrm{C} ; \mathrm{t}_{\max }=5\right.$ minutes $)$

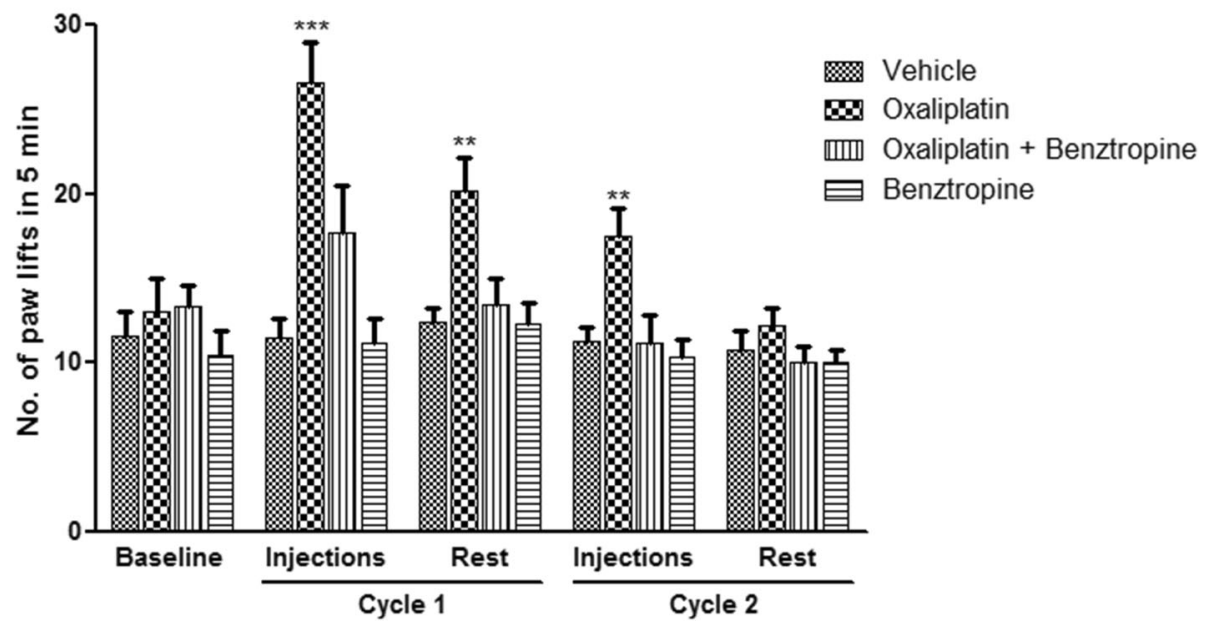

Fig. 1 In vivo effects of oxaliplatin and benztropine on acute oxaliplatin peripheral neuropathy. Evaluation of hyperalgesia required two 5-day cycles of daily oxaliplatin $(3 \mathrm{mg} / \mathrm{kg}$ ). Control mice received either oxaliplatin or vehicle alone. Cold hyperalgesia was evaluated using a cold plate set at $+2{ }^{\circ} \mathrm{C}$. Data are expressed as means \pm SEM of 7 different mice under each condition. ${ }^{*} p<0.05,{ }^{*} p<0.01,{ }^{* *} p<0.001$ versus vehicle

$17.25 \pm 0.87$ with vehicle, $p=0.2145)$ nor at any time point during the experiment (at week 6, $13.75 \pm 0.99$ with oxaliplatin plus benztropine versus $16.19 \pm 0.81$ with vehicle, $p=0.0659$ ) (Fig. 2b).

\section{In vivo effects of benztropine on diabetic mouse tactile hypoesthesia and hot hyperesthesia}

Since peripheral neuropathies can result from causes other than oxaliplatin infusions, we sought to investigate whether benztropine could alleviate painful symptoms brought about by other etiologies. Mice models of streptozotocin (STZ)-induced diabetes are robust and well-documented [81]. These mice develop peripheral neuropathies similar to those witnessed in diabetic patients. Diabetic mice developed diminished tactile perception from week $1(0.1780 \pm 0.0398$ in diabetic mice versus $0.0636 \pm 0.0173$ in non-diabetic mice, $p=0.0168$ ). Peak tactile hypoesthesia in diabetic mice was observed at the end of the testing period (week 6, $1.0800 \pm 0.0800$ in diabetic mice versus $0.1950 \pm 0.0481$ in non-diabetic mice, $p$ $<0.0001)$. Diabetic mice treated with benztropine did not display these symptoms of altered tactile hypoesthesia at week $1(0.0768 \pm 0.0191$ in benztropine-treated diabetic mice versus $0.0636 \pm 0.0173$ in non-diabetic mice, $p=$ 0.6153 ) nor at any time point during the experiment (at week $6,0.1200 \pm 0.0355$ in benztropine-treated diabetic mice versus $0.1950 \pm 0.0481$ in non-diabetic mice, $p=$ 0.2253) (Fig. 3a). Diabetic mice developed transient heat hyperalgesia from week 1 (7.70 \pm 0.68 in diabetic mice versus $11.00 \pm 0.75$ in non-diabetic mice, $p=0.0043$ ). Diabetic mice treated with benztropine did not display these symptoms of exacerbated pain to the hot plate at week $1(10.00 \pm 0.97$ in benztropine-treated diabetic mice versus $11.00 \pm 0.75$ in non-diabetic mice, $p=0.4232$ ) or symptoms of hot hypoalgesia at week $6(9.90 \pm 0.85$ in benztropine-treated diabetic mice versus $9.20 \pm 0.93$ in non-diabetic mice, $p=0.5849$ ), at which it peaked in diabetic mice (17.20 \pm 1.36 in diabetic mice versus $9.20 \pm 0.93$ in non-diabetic mice, $p=0.0001$ ) (Fig. 3b). Benztropine corrected both thermal perception abnormalities, namely transient hot hyperalgesia and persistent hot hypoalgesia, as well as tactile hypoesthesia in diabetic mice.

\section{In vivo effects of benztropine on sensory and} neuromuscular excitability of oxaliplatin-treated and diabetic mice

Oxaliplatin-treated mice presented significant alterations, consistent with membrane hyperexcitability, in sensory excitability variables, compared with control animals (i.e., mice injected with vehicle). In particular, the maximal CNAP amplitude was significantly reduced in oxaliplatin-treated mice compared to control mice $(0.026 \pm 0.012$ with oxaliplatin versus $0.041 \pm 0.012$ with vehicle, $p=0.0137)$. Associating benztropine to the chemotherapy abrogated this reduction $(0.037 \pm 0.009$ with oxaliplatin plus benztropine versus $0.041 \pm 0.012$ with vehicle, $p=0.4060$ ), while benztropine alone did not alter maximal CNAP $(0.040 \pm 0.009$ with benztropine versus $0.041 \pm 0.012$ with vehicle, $p=0.8096$ ) (Fig. 4, upper panel). The stimulus intensity required to give $50 \%$ of maximal CNAP amplitude was also altered in mice treated with oxaliplatin $(0.179 \pm 0.059$ with oxaliplatin versus $0.259 \pm 0.038$ with vehicle, $p=0.0041$ ). Associating benztropine to the chemotherapy abrogated 


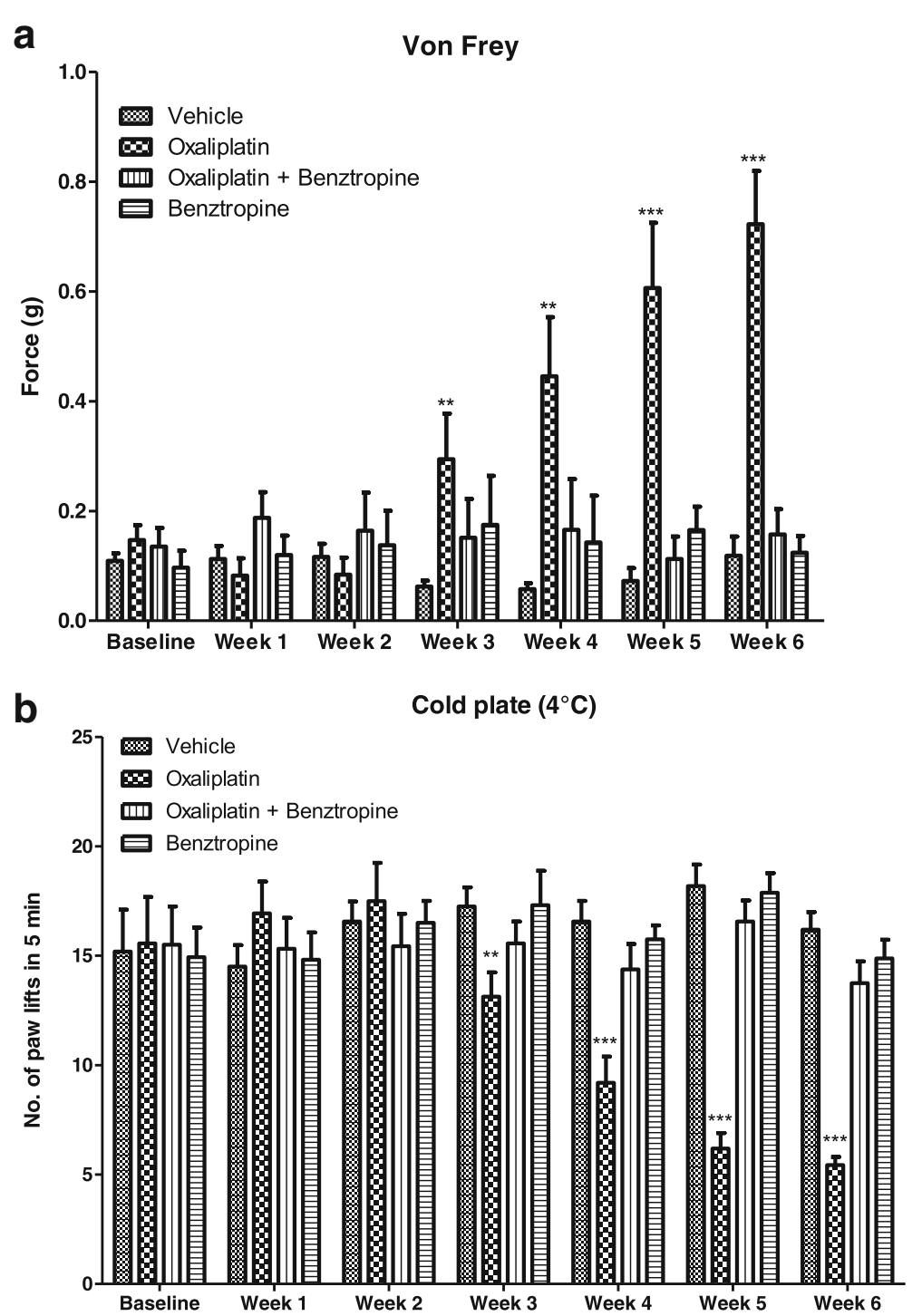

Fig. 2 In vivo effects of oxaliplatin and benztropine on chronic oxaliplatin peripheral neuropathy. $\mathbf{a}$ von Frey test and $\mathbf{b}$ cold-plate hypoesthesia test. Experimental mice received oxaliplatin $(10 \mathrm{mg} / \mathrm{kg})$ weekly and benztropine $(10 \mathrm{mg} / \mathrm{kg})$ daily for 6 weeks. Control mice received either oxaliplatin or vehicle alone. Both the von Frey and the cold-plate tests were performed on a weekly basis. Data are expressed as means \pm SEM of 8 different mice under each condition. ${ }^{*} p<0.05,{ }^{* *} p<0.01,{ }^{* * *} p<0.001$ versus vehicle

this reduction $(0.256 \pm 0.024$ with oxaliplatin plus benztropine versus $0.259 \pm 0.038$ with vehicle, $p=0.8090$ ), while benztropine alone did not alter this variable $(0.290 \pm 0.033$ with benztropine versus $0.259 \pm 0.038$ with vehicle, $p=0.0909$ ) (Fig. 4 , middle panel). Finally, an increased latency was observed in oxaliplatin-treated mice $(3.552 \pm 0.202$ with oxaliplatin versus $3.163 \pm 0.218$ with vehicle, $p=0.0014$ ). This increase was not observed when mice treated with the chemotherapy also received benztropine ( $3.187 \pm 0.220$ with oxaliplatin plus benztropine versus $3.163 \pm 0.218$ with vehicle, $p=0.8284$ ) or when mice received benztropine alone $(3.137 \pm 0.261$ with benztropine versus $3.163 \pm 0.218$ with vehicle, $p=$ 0.8230) (Fig. 4, lower panel). It is worth noting that the sensory alterations detected in oxaliplatin-treated mice were consistent with a decreased nerve conduction velocity, suggesting an apparent reduction in the number of fast-conducting fibers or decrease of density and/or functioning of transient sodium channels, and a modification in the voltage dependence of these channels.

Oxaliplatin-treated and diabetic mice also presented significant alterations, consistent with membrane hyperexcitability, in neuromuscular (motor) excitability waveforms and derived variables, compared with animals injected with vehicle (Additional file 1 and 2: Figure S1 and S2; Additional file 3: Table S1). These alterations mainly consisted of (i) an enhanced CMAP amplitude and a reduced stimulus intensity to evoke $50 \%$ of 


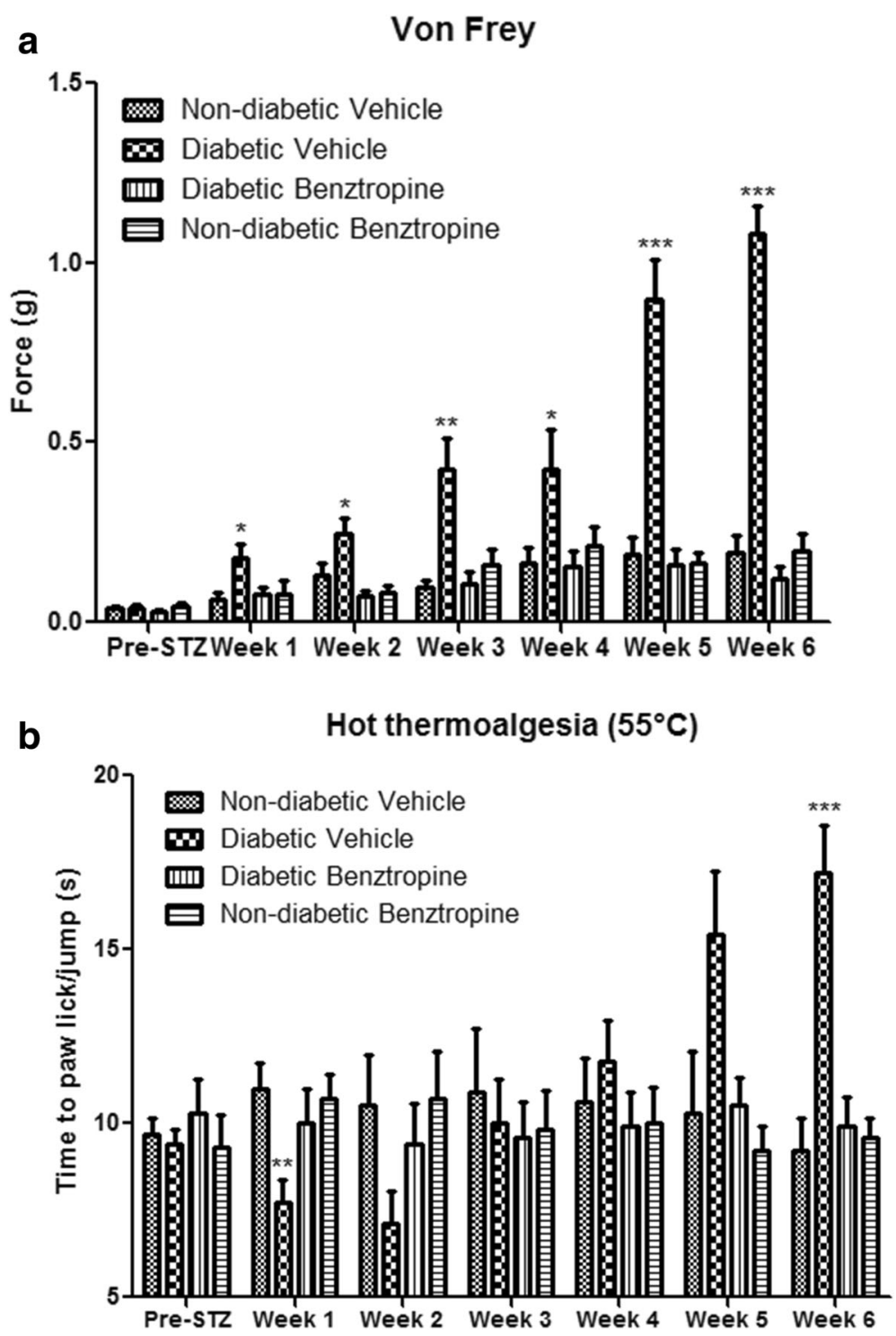

Fig. 3 In vivo effects of oxaliplatin and benztropine on diabetes-induced peripheral neuropathies. a von Frey test and $\mathbf{b}$ hot-plate test. Experimental diabetic mice received benztropine $(10 \mathrm{mg} / \mathrm{kg}$ ) daily for 6 weeks. Control mice received either benztropine or vehicle alone. Both, the von Frey as well as the hot-plate tests were performed on a weekly basis. Data are expressed as means \pm SEM of 8 different mice under each condition. ${ }^{*} p<0.05,{ }^{* *} p<0.01,{ }^{* *} p<0.001$ versus vehicle

maximal CMAP amplitude, suggesting an apparent decreased density and/or functioning of fast potassium channels and modification in the voltage dependence of transient sodium channels, respectively, with no change in the latency, i.e., no modification in the neurotransmission velocity; (ii) reduced minimum and hyperpolarizing slopes of the current-threshold relationship, indicating decreased density and/or functioning of cyclic nucleotide-gated channels; (iii) increased threshold changes in response to depolarizing and/or hyperpolarizing currents (threshold electrotonus), likely caused by reduced density and/or functioning of potassium channels; and (iv) lower superexcitability (recovery cycle), reflecting again fast potassium channel dysfunction. These alterations were not detected, or were greatly reduced, in oxaliplatin-treated and diabetic mice injected with benztropine, or in animals administered with benztropine alone.

In vitro effects of oxaliplatin and benztropine on excitability of mouse DRG sensory neurons

The in vitro effects of oxaliplatin, associated or not with benztropine, were assessed on the resting membrane and action potentials recorded from primary cultures of 


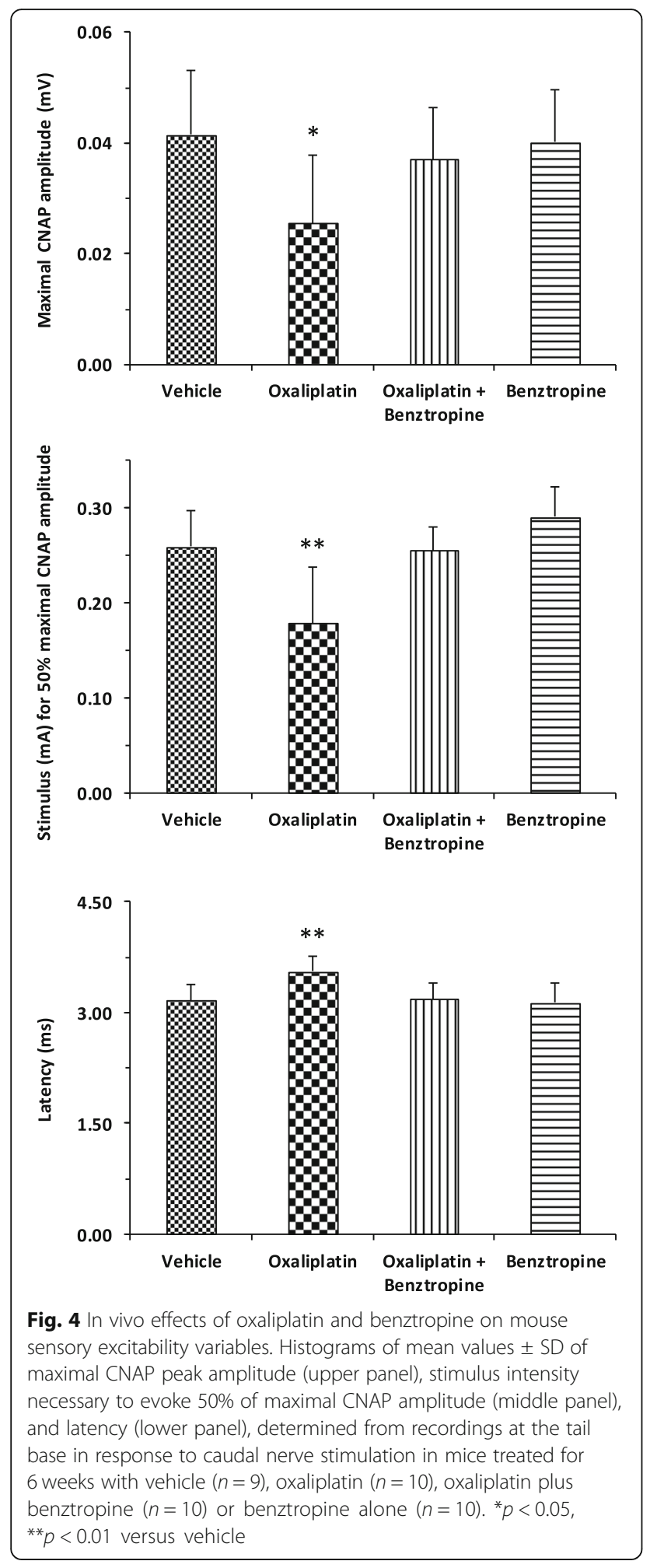

mouse DRG sensory neurons, using whole-cell patchclamp technique (Fig. 5). Recordings were performed on relatively small neurons since their mean \pm SD cell diameter (determined from their membrane capacity) was $21.6 \pm 4.5 \mu \mathrm{m}(n=18)$.
Under control conditions, two types of responses were recorded from neurons stimulated by $100-\mathrm{ms}$ current test-pulses: a single action potential (tonic response) from $39 \%(7 / 18)$ of cells, and more than one action potential (phasic response) from 61\% (11/18) of cells. The mean \pm SD ratio of the number of action potentials on the current intensity necessary to evoke action potentials was $0.007 \pm 0.001 \mathrm{pA}^{-1}(n=18)$. This ratio was significantly increased $(p=0.024)$ to $0.011 \pm 0.002 \mathrm{pA}^{-1}$ ( $n=$ 11) in the presence of $50 \mu \mathrm{M}$ oxaliplatin, due to both an increased number of action potentials in response to 100-ms current test-pulses and a decreased current intensity necessary to evoke action potentials, indicating membrane hyperexcitability of these neurons. When oxaliplatin $(50 \mu \mathrm{M})$ was added together with benztropine $(10 \mu \mathrm{M})$ to the standard external medium, the ratio returned to $0.005 \pm 0.002 \mathrm{pA}^{-1}(n=9)$, i.e., mean $\pm \mathrm{SD}$ values were not statistically different $(p=0.148)$ from those determined under control conditions.

The addition of oxaliplatin $(25$ or $50 \mu \mathrm{M})$ to the external medium bathing the neurons produced (i) about $20-\mathrm{mV}$ membrane depolarization identified by a reduced resting membrane potential, (ii) a significant decreased peak amplitude, and (iii) significant increased rise and decay times of action potentials, compared to control conditions. These modifications, indicating alterations in the density and/or functioning of both sodium and potassium channels, were greatly reduced, if not completely reversed, when oxaliplatin was added together with benztropine $(10 \mu \mathrm{M})$ to the external standard medium.

\section{Ex vivo effects of oxaliplatin and benztropine on mouse sciatic nerve fiber morphology and myelin protein content}

The morphology of myelinated axons of mouse sciatic nerves was assessed using confocal microscopy. Quantification of morphometric parameters of single myelinated axons revealed a significant increase in the nodal diameter, length and volume, as functions of the internodal diameter, in mice injected for 6 weeks with oxaliplatin, compared to vehicle-treated animals (Fig. 6, left panels; Additional file 4: Table S2). These results are likely the consequence of oxaliplatin-induced membrane hyperexcitability. In these animals, a reduction of the internodal diameter was also observed, which may reflect either a preferential loss of large myelinated nerve fibers or an alteration in myelin sheath layers surrounding the axons. These alterations of morphometric parameters were greatly reduced, if not absent, in mice injected for 6 weeks with oxaliplatin plus benztropine (Fig. 6, middle panels; Additional file 4: Table S2) or benztropine alone (Fig. 6, right panels; Additional file 4: Table S2). 

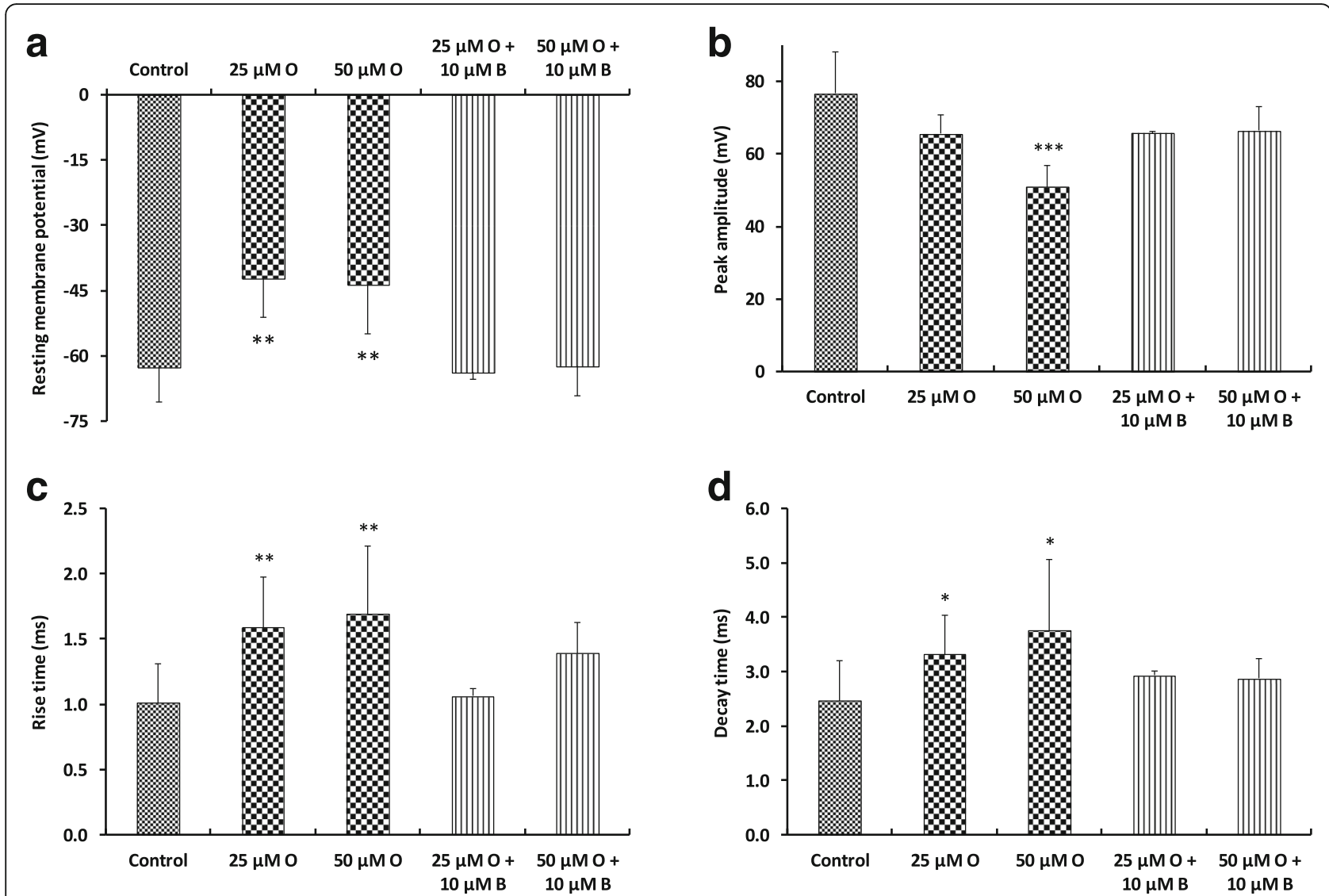

Fig. $\mathbf{5}$ In vitro effects of oxaliplatin, associated or not with benztropine, on excitability of mouse DRG sensory neurons, using whole-cell patch-clamp technique. Resting membrane potential (a), and action potential peak amplitude (b), rise time (c) and decay time (d) measured from recordings performed on DRG neurons before (control) and 10-20 min after addition of first 25-50 $\mu \mathrm{M}$ oxaliplatin (O) and then 25-50 $\mu \mathrm{M}$ oxaliplatin plus $10 \mu \mathrm{M}$ benztropine (B) to the standard physiological medium. Mean \pm SD of $5-18$ neurons. ${ }^{*} p=0.010-0.014,{ }^{* *} p=0.002-0.005$ and ${ }^{* * *} p<0.001$ versus control

The myelin sheaths of sciatic nerves from experimental and control groups of mice were also assessed using electronic microscopy. Analyses revealed a demyelination in oxaliplatin-treated mice compared to animals injected with vehicle, oxaliplatin plus benztropine or benztropine alone (Fig. 7). Semi-automated computerized measurement of myelin thickness allowed the quantification of the profound demyelination in sciatic nerves from oxaliplatin mice $(0.0344 \pm 0.0037$ with oxaliplatin versus $0.0233 \pm$ 0.0023 with vehicle, $p=0.007$ ). Associating benztropine to the chemotherapy abrogated the reduction in myelin sheath thickness observed in oxaliplatin mice $(0.0261 \pm$ 0.0019 with oxaliplatin plus benztropine versus $0.0233 \pm$ 0.0023 with vehicle, $p=0.346$ ). Benztropine did not impair myelin formation nor did it lead to excessive myelination $(0.0224 \pm 0.0038$ with benztropine versus $0.0233 \pm 0.0023$ with vehicle, $p=0.842$ ).

\section{Ex vivo effects of oxaliplatin and benztropine on mouse cutaneous nerve fiber density}

The density of cutaneous nerve fibers was examined in the paws of mice injected with vehicle, oxaliplatin, oxaliplatin plus benztropine or benztropine alone for 6-8 weeks (Fig. 8). Staining of the nerve fibers with PGP9.5 antibody revealed a reduced cutaneous nerve fiber density in paw skin of oxaliplatin-treated mice $(7.67 \pm 0.99$ with oxaliplatin versus $16.33 \pm 1.87$ with vehicle, $p=0.0022$ ). Benztropine abrogated this alteration in oxaliplatin-treated mice since the density of PGP9.5-stained nerves was maintained in these animals $(13.50 \pm 1.56$ with oxaliplatin plus benztropine versus $16.33 \pm 1.87$ with vehicle, $p=0.2728$ ). Benztropine alone did not alter cutaneous nerve fiber's integrity $(15.00 \pm 2.85$ with benztropine versus $16.33 \pm 1.87$ with vehicle, $p=0.7042$ ).

\section{Ex vivo study of myelin protein content in sciatic nerves} The myelin basic protein (MBP) expression was reduced in oxaliplatin-treated mice $(0.5825 \pm 0.1014$ with oxaliplatin versus $0.7125 \pm 0.1409$ with vehicle, $p=0.4823$ ), while co-administration of benztropine with the chemotherapy rescued this reduced expression of this key myelin protein $(0.6767 \pm 0.1172$ with oxaliplatin plus benztropine versus $0.7125 \pm 0.1409$ with vehicle, $p=$ 0.8603). It is worth nothing that MBP expression was 

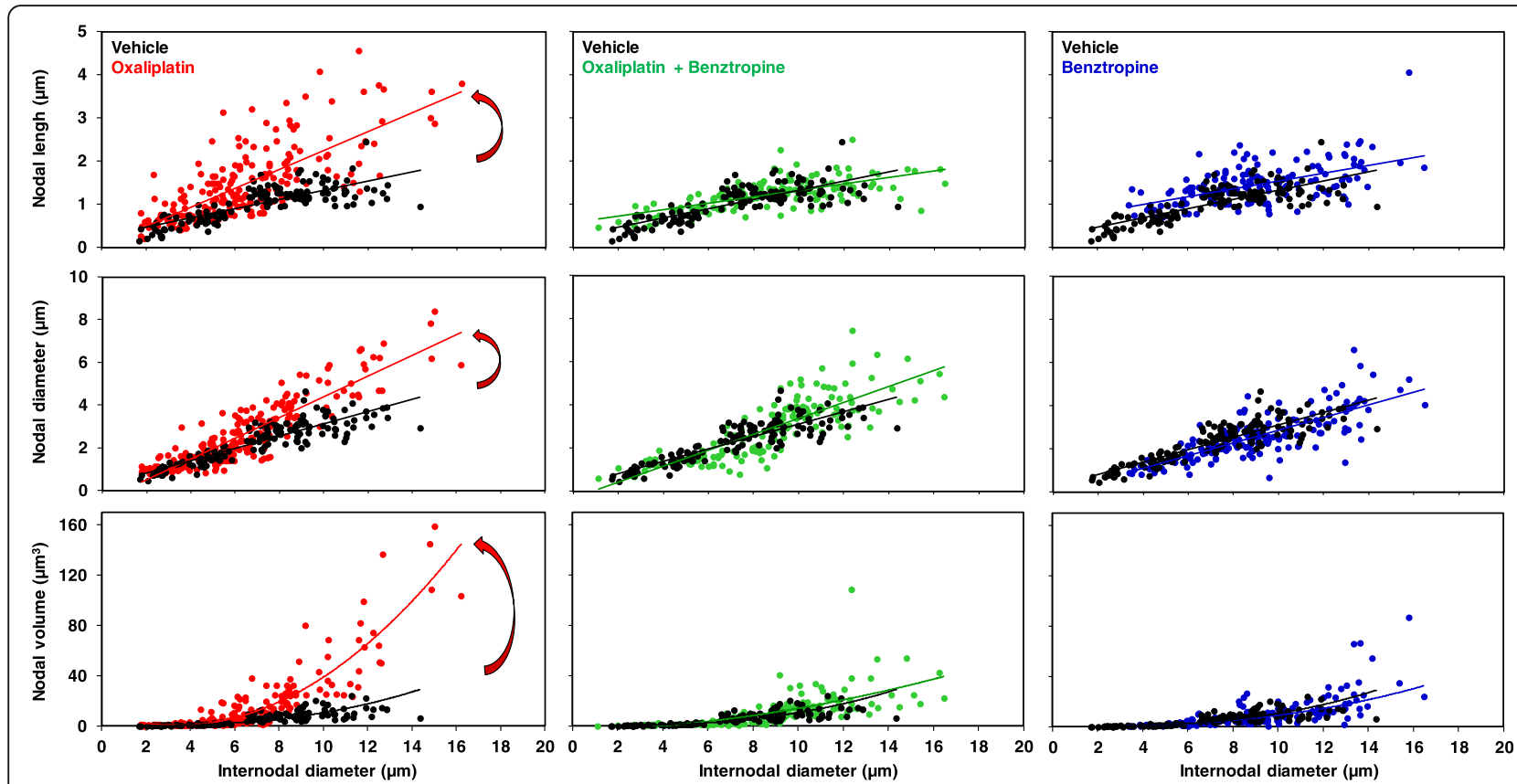

Fig. 6 Ex vivo effects of oxaliplatin and benztropine on the morphology of myelinated axons isolated from mouse sciatic nerves, using confocal microscopy. Representations of nodal length, diameter and volume, as functions of internodal diameter, of myelinated axons isolated from mice ( $n=4$ in each group) injected with vehicle (black closed circles, $n=137$ ), oxaliplatin (red closed circles, $n=206$ ), oxaliplatin plus benztropine (green closed circles, $n=150$ ) or benztropine alone (blue closed circles, $n=160$ ) for 6 weeks. The curves represent the linear (upper and middle panels) or non-linear (lower panels) fits of data points with $\mathrm{R}^{2}$ (correlation coefficients) between 0.441 and 0.877 . In left panels, the arrows underline the effects of oxaliplatin

identical in mice receiving benztropine alone and control animals $(0.7075 \pm 0.2781$ with benztropine versus $0.7125 \pm 0.1409$ with vehicle, $p=0.8603$ ) (Fig. 9).

Ex vivo effects of oxaliplatin and benztropine on systemic inflammatory markers

In order to evaluate the systemic effects of benztropine on pro-inflammatory cytokine levels, serum samples were analyzed (Fig. 10). Sera IL-6 levels were significantly increased in the oxaliplatin-treated group $(21.14 \pm 1.07 \mathrm{ng} / \mathrm{mL}$ with oxaliplatin versus $15.87 \pm 1.27 \mathrm{ng} / \mathrm{mL}$ with vehicle, $p=$ 0.0034). Associating benztropine to the chemotherapy prevented this systemic inflammation $(16.97 \pm 0.81 \mathrm{ng} / \mathrm{mL}$ with oxaliplatin plus benztropine versus $15.87 \pm 1.27 \mathrm{ng} /$ $\mathrm{mL}$ with vehicle, $p=0.4674$, and versus $21.14 \pm 1.07 \mathrm{ng} / \mathrm{mL}$ with oxaliplatin, $p=0.0042$ ). Benztropine alone did not induce any changes in IL-6 levels $(15.12 \pm 1.28 \mathrm{ng} / \mathrm{mL}$ with benztropine versus $15.87 \pm 1.27 \mathrm{ng} / \mathrm{mL}$ with vehicle, $p=$ 0.6829). Sera TNF- $\alpha$ levels were also significantly increased in the oxaliplatin-treated group compared to the control group $(84.18 \pm 6.86 \mathrm{pg} / \mathrm{mL}$ with oxaliplatin versus $58.36 \pm$ $7.27 \mathrm{pg} / \mathrm{mL}$ with vehicle, $p=0.0150)$. Similar to its effects on IL-6 levels, benztropine also prevented the significant increase in TNF- $\alpha$ levels observed in oxaliplatintreated-animals $(54.36 \pm 5.17 \mathrm{pg} / \mathrm{mL}$ with oxaliplatin plus benztropine versus $58.36 \pm 7.27 \mathrm{pg} / \mathrm{mL}$ with vehicle, $p=0.6570$, and versus $84.18 \pm 6.86 \mathrm{pg} / \mathrm{mL}$ with oxaliplatin, $p=0.0016)$. Benztropine on its own induced a slight, but non-significant, decrease in TNF- $\alpha$ levels $(47.30 \pm 5.17 \mathrm{pg} / \mathrm{mL}$ with benztropine versus $58.36 \pm$ $7.27 \mathrm{pg} / \mathrm{mL}$ with vehicle, $p=0.2246$ ).

In vivo effects of benztropine on oxaliplatin-induced tumor growth in mice

Results obtained from neurological tests provided a rationale to use benztropine as a neuroprotective drug. However, further data regarding its effect on oxaliplatin efficacy had to be gathered to guarantee its safety in addressing the primary aspect of the condition which is tumor growth (Fig. 11). From day 6 of treatment, benztropine displayed antitumor efficacy upon association with oxaliplatin (tumor size of $333.5 \pm 42.3 \mathrm{~mm}^{3}$ with oxaliplatin plus benztropine versus $832.1 \pm 105.8 \mathrm{~mm}^{3}$ with vehicle, $p=0.0009$ ). Moreover, from day 6 treatment, benztropine potentiated the chemotherapy response (tumor size of $333.5 \pm 42.3 \mathrm{~mm}^{3}$ with oxaliplatin plus benztropine versus $624.8 \pm 69.8 \mathrm{~mm}^{3}$ with oxaliplatin, $p=$ 0.0039 ), while oxaliplatin alone had not yet demonstrated antitumor efficacy (tumor size of $624.8 \pm 69.8 \mathrm{~mm}^{3}$ with oxaliplatin versus $832.1 \pm 105.8 \mathrm{~mm}^{3}$ with vehicle, $p=$ 0.1279). At the end of the experiment, when the largest 
a
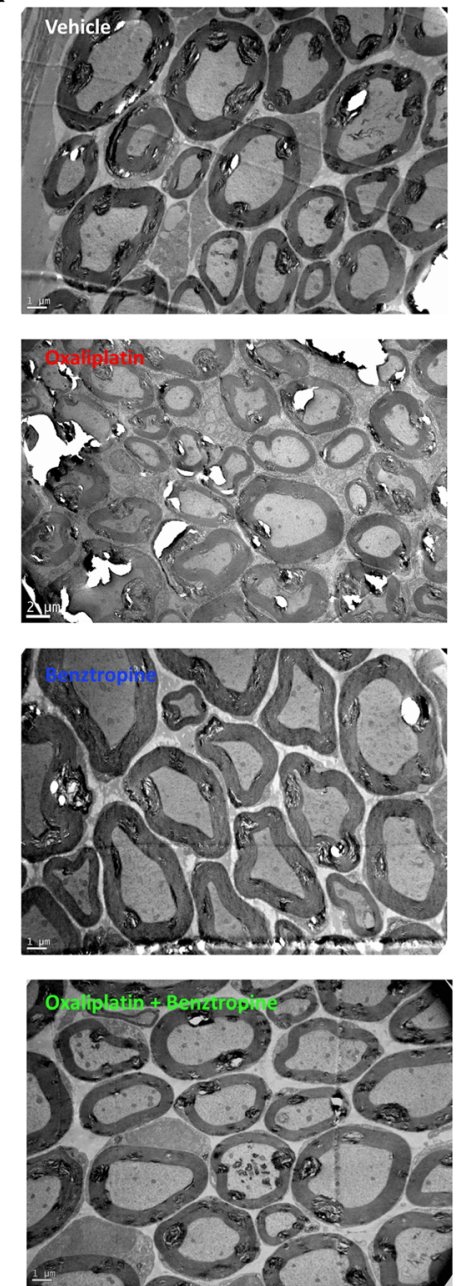

b

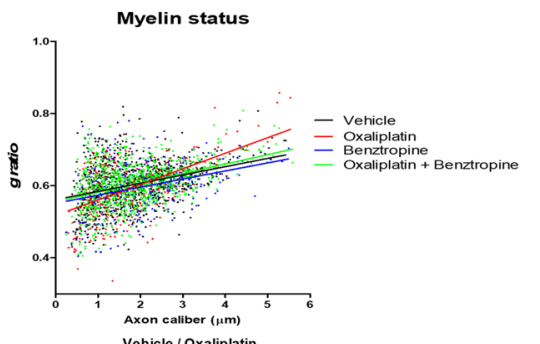

Vehicle / Oxaliplatin

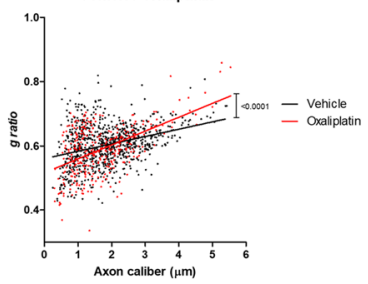

Oxaliplatin / Benztropine
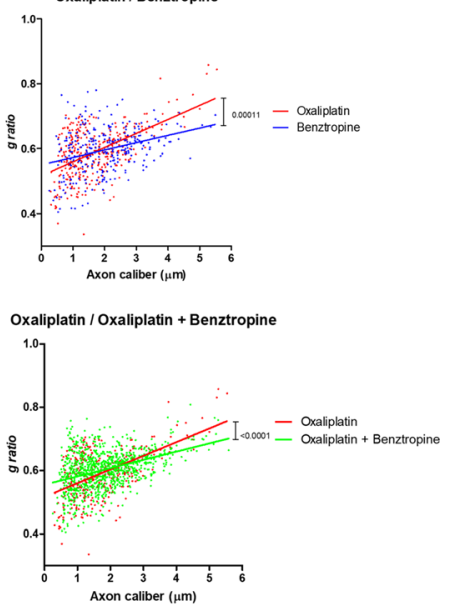

Fig. 7 Effect of benztropine on demyelination and axonal atrophy in oxaliplatin-treated mice. a Representative images of EM micrographs of ultrathin cross-sections of sciatic nerves from vehicle, oxaliplatin, benztropine and oxaliplatin plus benztropine animals at 6 weeks. $\mathbf{b}$ Quantification of myelin state though g-ratio analysis reported to axonal caliber. At least 200 axons per animal $(n=2-3)$ were analyzed. The curves are linear regression fits of data points. ${ }^{*} p<0.05,{ }^{* *} p<0.01$

tumors had reached ethical guidelines' endpoint, mice which received benztropine associated with oxaliplatin presented the lowest tumor burden $\left(687.5 \pm 103.3 \mathrm{~mm}^{3}\right.$ with oxaliplatin plus benztropine versus $4721.0 \pm 560.0$ $\mathrm{mm}^{3}$ with vehicle, $\left.p<0.0001\right)$. In addition, mice which received benztropine alone displayed smaller, although non-significant, tumors compared to control mice $\left(4132.0 \pm 522.8 \mathrm{~mm}^{3}\right.$ with benztropine versus $4721.0 \pm$ $560.0 \mathrm{~mm}^{3}$ with vehicle, $p=0.4571$ ).

\section{In vitro effects of oxaliplatin associated or not with benztropine on cultured cell viability}

The in vitro neuroprotective potential of benztropine on oxaliplatin-induced peripheral neuropathies was assessed on N2a neuron-like cells. The effects of benztropine on oxaliplatin-induced anti-tumor effect was also evaluated in vitro on CT26 colon carcinoma cell lines. Our results indicate that oxaliplatin has a cytotoxic effect on both N2a and CT26 cells. Benztropine modulates cell viability in a cell-type-dependent manner. Benztropine potentiated oxaliplatin cytotoxicity on CT26 cells (Fig. 12a). Inversely, in benztropine-treated neuron-like N2a cells, the cytotoxicity of oxaliplatin was reduced with a viability increased from $56 \%$ without benztropine to $70 \%$ with benztropine (Fig. 12b). Moreover, in cells treated with $6.25 \mu \mathrm{M}$ oxaliplatin, co-incubation with $15 \mu \mathrm{M}$ of benztropine induced a significant decrease of GSH in CT26 cells $(2141 \pm 120$ versus $2931 \pm 142$ in untreated cells, $p<0.05$, Fig. 12c) but a significant increase of GSH in N2a $(18,344 \pm 634$ versus $11,355 \pm 934$ in untreated cells, $p<0.001$, Fig. 12d). ROS production evidenced by H2DCFDA staining was stimulated in both cell types treated with oxaliplatin. However, 


\section{a}

MBP 18-20kD

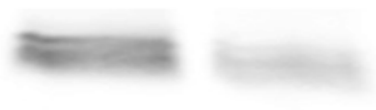

sim

B-actine
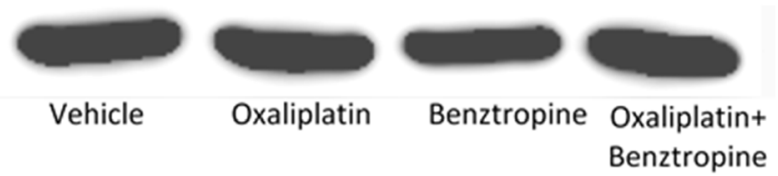

b

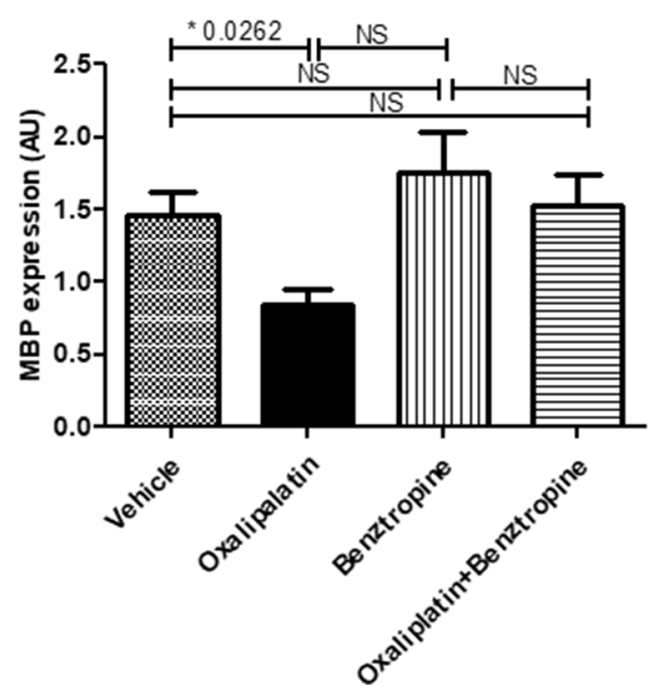

Fig. 8 Effect of benztropine cutaneous nerve fiber density reduction induced by oxaliplatin. a Representative images of staining with PGP9.5 of cutaneous nerve fibers. b Analysis of cutaneous nerve fiber density from paw skin samples $(6 \mu \mathrm{m})$ of mice treated for 6 weeks with vehicle, oxaliplatin, oxaliplatin plus benztropine or benztropine alone. Mean \pm SEM of 8 mice. ${ }^{*} p<0.05$, ${ }^{* *} p<0.01$. NS: non-significant. Scale bar $=50 \mu$ m

benztropine at a concentration of 7.5 and $15 \mu \mathrm{M}$ decreased oxaliplatin-induced ROS production in N2a cells $(p<0.05)$ (Fig. 12f) and, in contrast, $15 \mu \mathrm{M}$ of benztropine increased oxaliplatin-induced ROS production in CT26 cells $(\mathrm{p}<0.05$ to $p<0.01)$ (Fig. 12e).

\section{Discussion}

Peripheral neuropathy is one of the most prevalent neurologic conditions encountered by physicians of all specialties [88] and is frequently associated with viral, toxic or metabolic etiologies [60]. Despite its high prevalence, no efficient curative treatment is available to decrease peripheral neuropathic pain and disability [24]. In this report, we demonstrate that benztropine, an inhibitor of acetylcholine (ACh) muscarinic M1 and M3 receptors (mAChR) [22], improves both acute and chronic clinical symptoms of experimental peripheral neuropathies in mice induced either by treatment with the chemotherapeutic drug oxaliplatin or with streptozotocin (STZ) in a model of diabetes-induced peripheral neuropathy $[81,86]$.

In order to better understand the mechanisms of this protection at neuronal levels, we performed electrophysiological tests to evaluate sensory and neuromuscular excitability. Oxaliplatin-treated mice presented significant reductions of the maximal CNAP amplitude and of the stimulus intensity required to give $50 \%$ of maximal CNAP as well as an increase in latency, both these signs being associated with membrane hyperexcitability. The sensory alterations detected in oxaliplatin-treated mice were consistent with a decreased nerve conduction velocity, suggesting an apparent reduction in the number of fast-conducting fibers or a decrease of density and/or functioning of transient sodium channels, and a modification in the voltage dependence of these channels. These alterations were all prevented by treatment with benztropine. The in vitro effects of oxaliplatin on the resting membrane and action potentials recorded from primary cultures of mouse DRG sensory neurons using whole-cell patch-clamp showed modifications characteristic of alterations in the density and/or functioning of both sodium and potassium channels. These alterations were greatly reduced, if not completely reversed, when the anticancer agent was added together with benztropine $(10 \mu \mathrm{M})$ to the external standard medium.

Oxaliplatin is known to exhibit a tetrodotoxin-like inhibitory effect on neuronal voltage-gated sodium $(\mathrm{Na}+)$ channels $[1,8,89]$. It remarkably slows their inactivation and reduces the peak $\mathrm{Na}+$ current, leading to an increase in the duration of the relative refractory period of sensory 


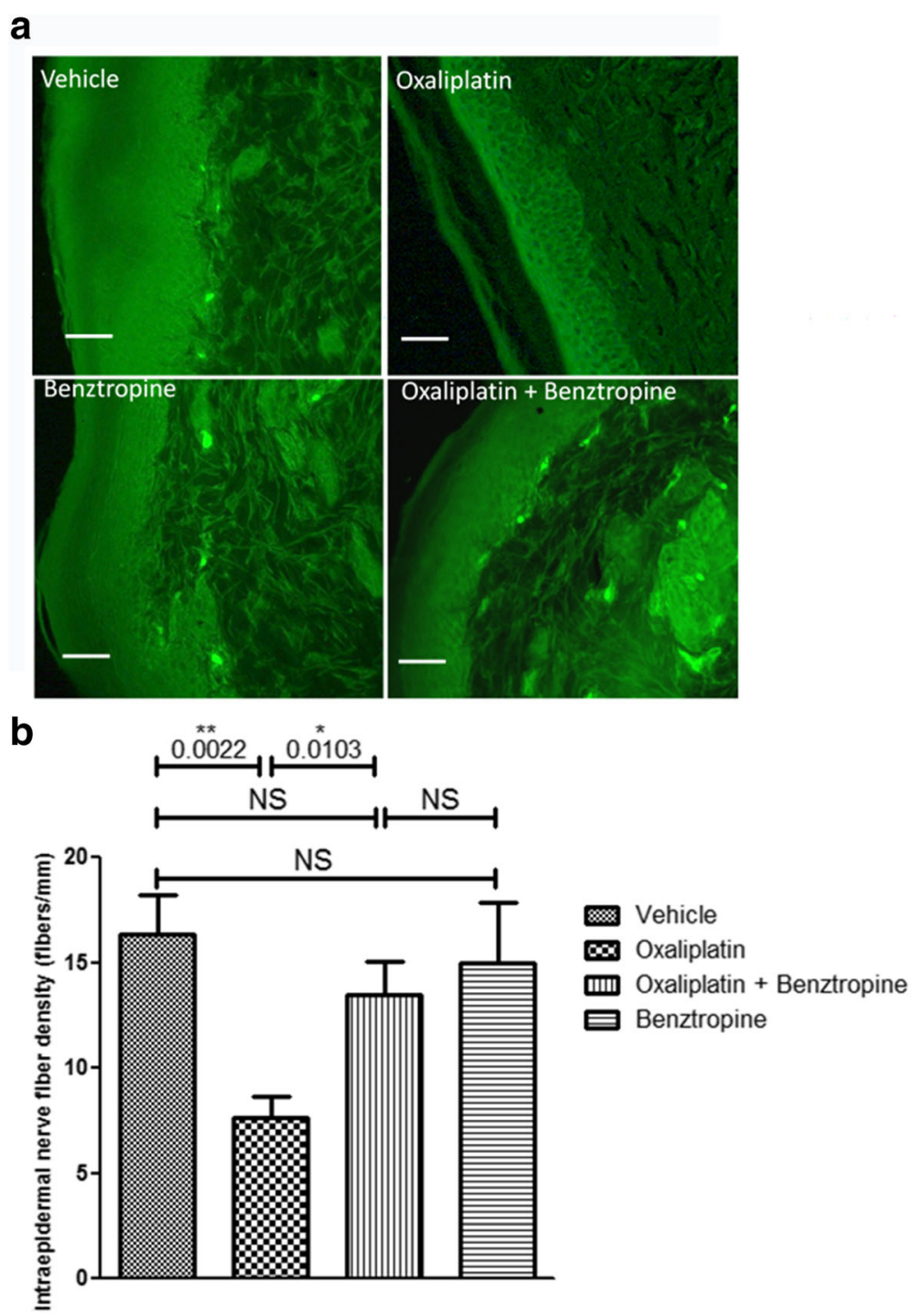

Fig. 9 Effect of benztropine on MBP expression in the sciatic nerves of oxaliplatin-treated mice. Western blot analyses of total protein lysates from brain sciatic nerves of control, and treated mice. $\mathbf{a}$ panel shows detection of MBP and $\mathbf{b}$ panel shows anti- $\beta$-actin for loading control. NS: non-significant

neurons that become hyperexcitable. Oxaliplatin may also affect the $\mathrm{Na}+$ channels indirectly via the chelation of extracellular calcium ions by its metabolite oxalate (diaminocyclohexane-platinum-C2O4) [1]. Peripheral nerve axonal excitability studies performed after oxaliplatin administration in vivo have revealed acute abnormalities in sensory nerve function related to $\mathrm{Na}+$ channel dysfunction, including decreased refractoriness and increased superexcitability [63]. The effects of oxaliplatin on the Nav1.6 voltage-gated $\mathrm{Na}+$ channel isoforms have been associated with the development of unique neuropathy symptoms such as cold-aggravated peripheral pain [23, 76]. In rat hippocampal neurons, muscarinic receptor agonists modulate $\mathrm{Na}+$ channel activity through activation of PKC [12]. In the periphery, the implication of PKC activation in nociceptive neurons has been largely studied and linked to hyperexcitability and hyperalgesia through upregulation of both Nav1.8 and Nav1.9 [47, 90]. Blocking PKC by muscarinic antagonists could be relevant to prevent peripheral neuropathies, as PKC inhibition has been shown to prevent hyperalgesia in an in vivo model of diabetic neuropathy [41].

Kagiava et al. [40] suggested that altered voltage-gated potassium channel activity may also be involved in oxaliplatin-induced neurotoxicity. Oxaliplatin was found to cause broadening of action potentials and repetitive firing, suggesting its antagonistic effect on fast and slow neuronal potassium channels. Many sensory neurons in rat dorsal root ganglia express Kv7.2, Kv7.3 and Kv7.5. These channels are known as $\mathrm{M}$ channels and are closed by receptors coupled to Gq such as M1 and M3 muscarinic receptors. This blockade increases neuronal excitability and underlies 


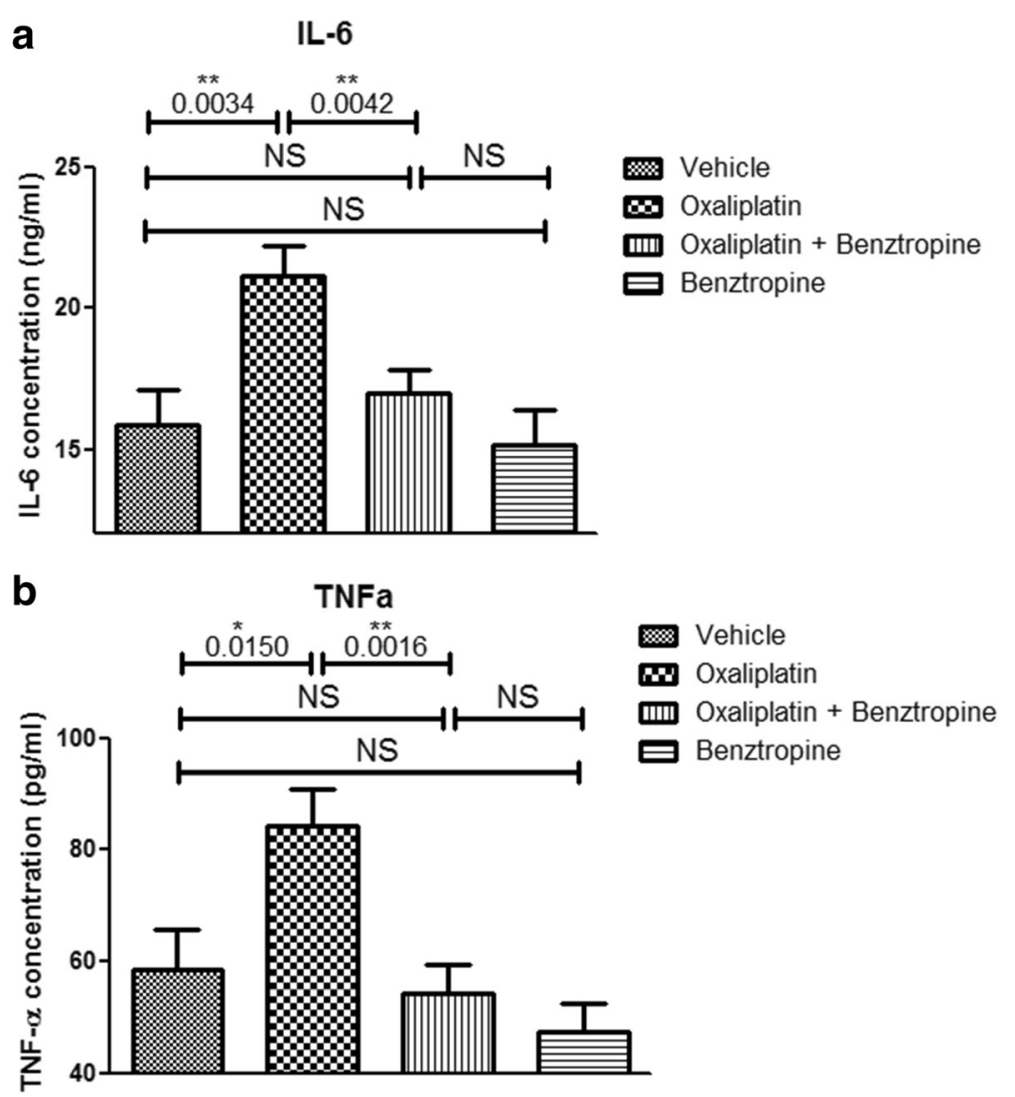

Fig. 10 Sera inflammatory markers. a ELISA-quantified levels of IL-6 in sera from mice treated for 6 weeks with vehicle, oxaliplatin, oxaliplatin plus benztropine or benztropine alone. b ELISA-quantified levels of TNF-a in sera from mice treated for 6 weeks with vehicle, oxaliplatin, oxaliplatin plus /benztropine or benztropine alone. Data are mean \pm SEM of 8 mice. ${ }^{*} p<0.05,{ }^{* *} p<0.01,{ }^{* *} p<0.001$ versus vehicle. NS: non-significant

\section{Tumor growth}

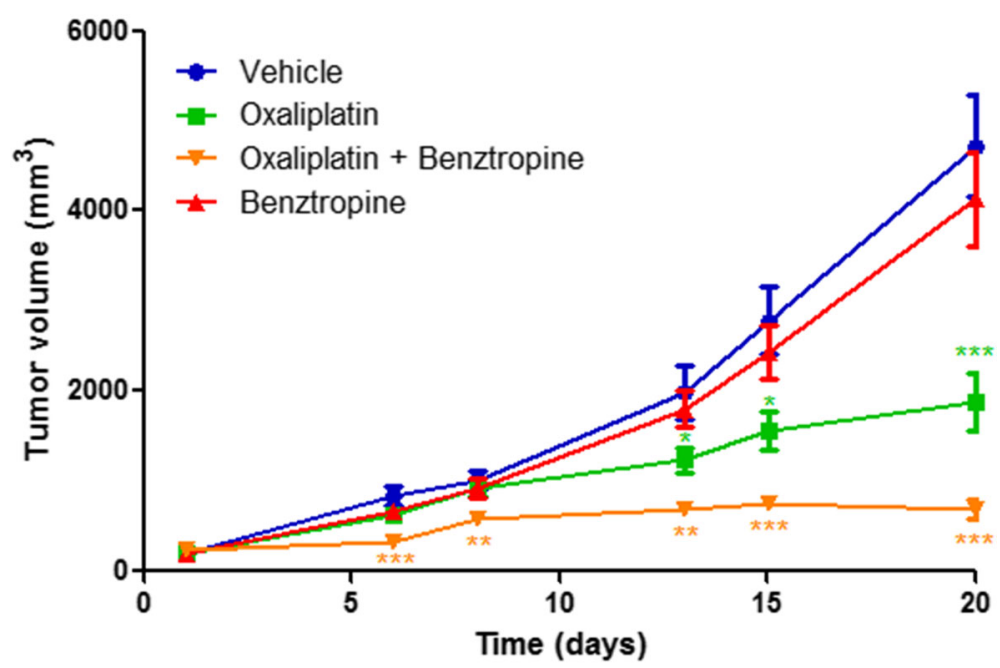

Fig. 11 Benztropine prevents tumor growth and displays a synergistic antitumoral effect when associated with oxaliplatin in an ectopic model of colorectal cancer. Tumor size in mice injected subcutaneously into the back with 106 CT26 cells and treated with vehicle, oxaliplatin, oxaliplatin associated with benztropine or benztropine alone. Data are mean \pm SEM of 8 tumor volume under each condition. ${ }^{*} p<0.05,{ }^{* *} p<0.01,{ }^{* * *} p<0.001$ versus vehicle 
a

\section{CT26}
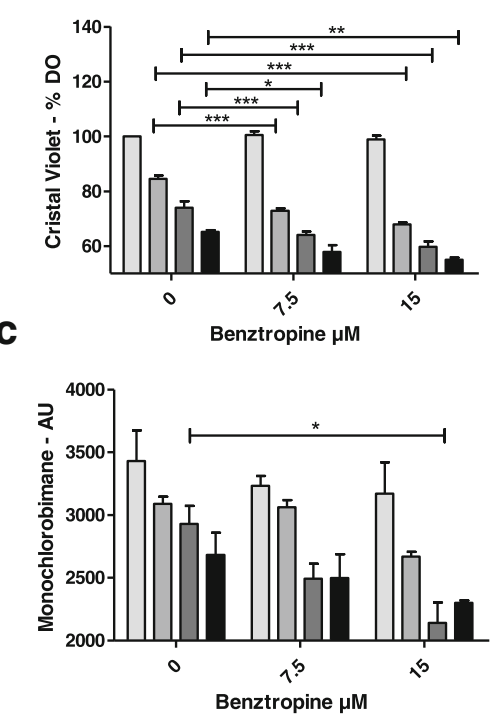

e

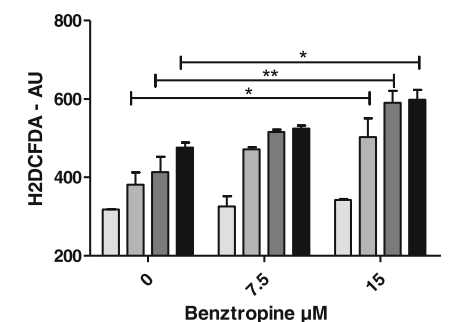

b

N2a

d
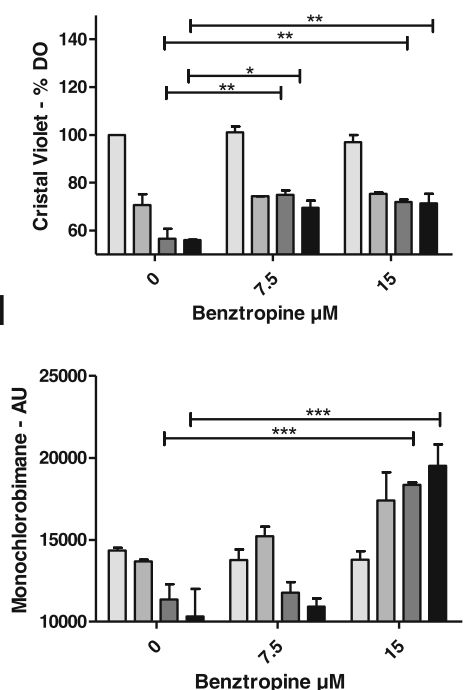

f

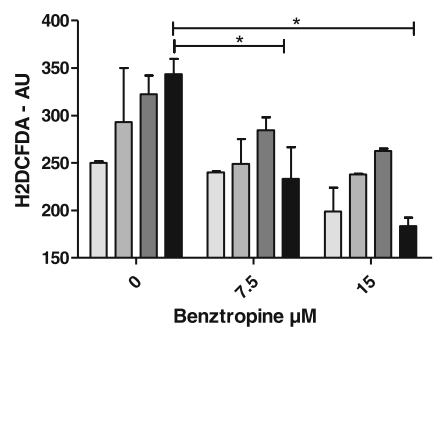

Fig. 12 In vitro effects of oxaliplatin associated or not with benztropine on cell viability, GSH and ROS production. Viability was expressed as percent \pm SEM versus cells in culture medium alone (100\% viability) in CT26 cells (a) and N2a cells (b). GSH was measured using the monochlorobimane dye in CT26 cells (c) and N2a cells (d). ROS generation was measured using H2DCFDA fluorescent emission when converted to the highly fluorescent DCF in CT26 cells (e) and N2a cells (f). Data from at least 4 independent experiments have been pooled and were expressed as means \pm SEM of triplicates. ${ }^{*} p<0.05,{ }^{* *} p<0.01$ versus oxaliplatin

some forms of cholinergic excitation. By contrast, their activation attenuates sensory $\mathrm{A} \delta$ and $\mathrm{C}$-fibre discharges induced by heat stimulation when applied to the peripheral endings of sensory fibres in the isolated rat skin nerve preparation [64], and increases the threshold for C-fiber stimulation in human sural nerves [48]. These experiments clearly demonstrate the presence of $\mathrm{Kv} 7 / \mathrm{M}$-channels at various sites along the sensory neuraxis and also indicate the therapeutic potential of enhancing their activity [10]. Interestingly, Sittl et al. [75] showed that enhancement of axonal potassium conductance by flupirtine, a Kv7/ M-channel enhancer could reduce oxaliplatin-induced peripheral nerve hyperexcitability, supporting our findings that blockade of muscarinic receptor M1 and M3 by benztropine can produce the same effects.

Oxaliplatin-treated and diabetic mice also presented significant alterations, consistent with membrane hyperexcitability, in neuromuscular (motor) excitability waveforms and derived variables, compared with animals injected with vehicle, suggesting an apparent decreased density and/or functioning of fast potassium channels and modification in the voltage dependence of transient sodium channels, respectively; decreased density and/or functioning of cyclic nucleotide-gated channels; reduced density and/or functioning of potassium channels. These alterations were not detected, or were greatly reduced, in oxaliplatin-treated and diabetic mice injected with benztropine, or in animals administered with benztropine alone. At the neuromuscular levels, oxaliplatin has been shown to increase both evoked and spontaneous neurotransmitter release in the motor nerve terminal of a phrenic nerve hemidiaphragm preparation [89]. The hyperexcitability effects of oxaliplatin on the mammalian neuromuscular junction appear related to a mechanism 
which delays entry of $\mathrm{Na}+$ channels into an inactivated state and, to a lesser extent, to a reduced $\mathrm{K}+$ channel activity, both of which can be prevented by benztropine.

Electronic microscopy of the myelin sheaths of the sciatic nerves revealed a demyelination in oxaliplatintreated mice compared to animals injected with vehicle alone, oxaliplatin plus benztropine or benztropine alone. Confocal microscopy of mouse sciatic nerves confirms the alteration of the morphology of myelinated axons with a significant increase in the nodal diameter, length and volume, as functions of the internodal diameter, in oxaliplatin-treated mice compared to vehicle-treated animals. These results are likely the consequence of oxaliplatin-induced membrane hyperexcitability as previously described [8]. In these animals, a reduction of the internodal diameter was also observed, which may reflect either a preferential loss of large myelinated nerve fibers or an alteration in myelin sheath layers surrounding the axons. The drop in MBP expression in oxaliplatin-treated animals confirmed the severe reduction of neuron myelination in DRG and sciatic nerves. These alterations of morphometric parameters were greatly reduced, if not absent, in mice co-injected with oxaliplatin and benztropine. In a recent study, Imai and coworkers [37] showed that treatment with oxaliplatin induced cytotoxicity of myelin-forming Schwann cells accompanied by mitochondrial dysfunction at concentrations lower than those impairing DRG neurons. These direct effects of oxaliplatin on Schwann cells might be an underlying cause of CIPN in addition to its direct toxicity in peripheral neurons. Schwann cells express muscarinic receptors M1, M2, M3, and M4 [27, 55] and localize to the axon-Schwann cell boundary [67]. Activation of AChR on Schwann cells modified the myelin sheet by altering the viscosity of the myelin membrane [84] that can be prevented by muscarinic receptor antagonists.

A severe reduction in the number of cutaneous nerve fibers is frequently observed in humans and mice treated with oxaliplatin as a result of neuronal toxicity of the platinum compound. Interestingly, benztropine also prevented the drop in neuronal density in the paws of mice injected with oxaliplatin. It has recently been demonstrated that neurite outgrowth is controlled by muscarinic receptors through regulation of mitochondrial function. M1R-deficient mice rended diabetic with STZ are protected from physiological and structural indices of sensory neuropathy and pharmacological blockade of M1R using antimuscarinic drugs prevented or reversed indices of diabetic or chemotherapy-induced peripheral neuropathy [11].

Proinflammatory cytokines like TNF $\alpha$ or IL- 6 contribute to axonal damage, alteration of the myelin structure and voltage dependent channel integrity but also modulate spontaneous nociceptor sensitivity and activity by increasing $\mathrm{Na}+$ and $\mathrm{Ca} 2+$ currents at the nociceptor peripheral terminals, which results in an increased membrane excitability, and a reduction in pain threshold and peripheral sensitization [43]' [20,71]. The pain sensation in distal extremities has been attributed to dysfunction of small myelinated A $\delta$ or unmyelinated C-fibers [28, 85]. Sensitizing uninjured adjacent nerve fibers (nociceptors) or sensory neurons by proinflammatory cytokines plays a critical role in the development of the chemotherapy- and diabetic-induced painful peripheral neuropathy as evidenced by numerous clinical and experimental studies $[57,71]$. Indeed, following intravenous administration of chemotherapy drugs, an important activation of Schwann cells along with a massive infiltration of activated macrophages in the DRG and in peripheral nerves leads to a subsequent production and secretion of inflammatory cytokines like TNF $\alpha$, IL-1 $\beta$ and IL-6; promoting neuroinflammation with allodynia and hyperalgesia [65]. Injection of an anti-IL-6 neutralizing antibody alleviated pain-related behaviors [59, 83] and a recent clinical study reported that IL-6 levels were significantly higher after the conclusion of chemotherapy in breast cancer patients with CIPN than in those without CIPN, providing the first clinical evidence of the involvement of IL-6 in CIPN [78]. In diabetes, an enhanced expression of the NF-kB-derived cytokine TNF $\alpha$ in the sciatic nerve of diabetic rats and mice was associated with decreased expression of myelin basic protein and with both large and small nerve fiber dysfunction, as documented by reductions in the motor and sensory nerve conduction velocities and in the intraepidermal nerve fiber density in the diabetic animals [42]. These neuronal dysfunctions were all reverted by blocking TNF with a recombinant human TNF receptor-antibody fusion protein [73]. Interestingly, neurons and immune cells, especially macrophages, express all five muscarinic receptors and their stimulation promotes a pro-inflammatory reaction while blocking the M1 and M3 receptors has been shown to reduce the synthesis of the pro-inflammatory cytokines IL-6 and TNF $\alpha$ [29].

In addressing the primary aspect of the condition, which is tumor growth, we found that mice receiving benztropine alone had a reduced size of tumors compared to untreated animals and when associated with oxaliplatin presented the lowest tumor burden compared to mice treated with oxaliplatin alone. These data are in line with the role of muscarinic receptors on tumor growth and especially on colon cancer progression. Indeed, the levels of expression and activation of M3 muscarinic receptors in colon cancer cells are very high and associated with increased tumor cell proliferation by activation of the MAPKinase pathways and invasiveness by increasing 
MMP1 release. All of these effects are reduced by M3R antagonists [26].

Benztropine exerts an original effect on neuronal cells by increasing the level of reduced glutathione thus reducing ROS levels induced by oxaliplatin and cell death. Blocking muscarinic receptors has already been associated with a reduction in ROS release, prevention of glutathione depletion and enhanced viability in various normal non tumoral cell types [82]. By contrast, benztropine potentiates the cytotoxic effect of oxaliplatin on tumor cells via a drop in GSH levels and an increase in $\mathrm{H}_{2} \mathrm{O}_{2}$ production, in line with the capacity of benztropine to reduce neuronal toxicity while maintaining the anti-tumor efficacy of oxaliplatin. Activation of the M1 muscarinic receptor by various agonists decreases SOD activities and induces superoxide anion production in neuronal cells [56]. Interestingly, superoxide anions have been shown to be particularly cytotoxic for neurons upon exposure to oxaliplatin, as superoxide dismutase mimics prevent oxaliplatin-induced neuropathies while increasing the anti-tumoral effect of the chemotherapy on colon cancer cells [18]. SOD increase by M1 blockade leads to superoxide anions dismutation into $\mathrm{H}_{2} \mathrm{O}_{2}$, whose cytotoxicity towards tumor cells adds up to that of oxaliplatin. The differences observed between normal and tumor cells fate upon oxaliplatin and benztropine exposure can be related to their different basal levels of $\mathrm{GSH}$ and responses towards a $\mathrm{H}_{2} \mathrm{O}_{2}$-mediated stress [3, 49, 62, 80]. Tumor cells are more sensitive to ROS-induced cell death than normal cells due to increased metabolism of tumor cells and antioxidant defense exhaustion. Indeed, in normal cells, similar levels of $\mathrm{H}_{2} \mathrm{O}_{2}$ that kill tumor cells favor cellular viability and proliferation through adaptation and mobilization of antioxidant defenses, usually through NRF2 induction [33]. Furthermore, GSH homeostasis is of prime importance for neurons as their depletion in this antioxidant molecule ultimately leads to their senescence mediated by oxidative stress [7]. Several studies concur with the observation that GSH-mediated detoxification of $\mathrm{H}_{2} \mathrm{O}_{2}$ is paramount to address neurologic disorders, may they be central or peripheral $[5,69]$. In clinical settings, GSH infusions significantly reduce the severity of the neurodegenerative side effects of oxaliplatin [14].

\section{Conclusion}

In the present study, we show that benztropine inhibits the oxaliplatin adverse effects mainly focusing on its anti-muscarinic action. However, benztropine also presents additional pharmacologic properties. Indeed, benztropine is a $\mathrm{H} 1$ receptor antagonist and an inhibitor of the dopamine re-uptake. Those properties are relevant since Khalilzadeh E et al. demonstrated that $\mathrm{H} 1$ receptor antagonists could attenuate the mechanical allodynia and prevented cold plate avoidance in a rat model of neuropathic pain [44]. Such observation has never been made in CIPN. However, we cannot rule out that the improvement of neuropathy we observed in our model was due to, at least in part, the anti-histaminic effect of benztropine. Moreover, benztropine also acts as a dopamine re-uptake inhibitor. It has been shown by Hache G et al. that administration of drugs that enhance the activity of dopamine neurotransmission also provide antinociceptive effects [35]. Therefore, we cannot exclude that the dopamine re-uptake inhibition by benztropine may participate in the prevention of oxaliplatin-induced peripheral neuropathy.

Finally, even though M1 and M3 muscarinic receptors inhibition remains the major mechanism regulated by benztropine to counteract CIPN and tumor growth, we cannot rule out that its effects on $\mathrm{H} 1$ histaminic receptors and dopamine re-uptake may also participate in the beneficial effects of benztropine. Therefore more detailed studies are needed to investigate the relative contribution of these pathways.

A limitation of this study is that results have been gained in animals only. However, the literature indicates that murine models of peripheral neuropathies are robust models for modeling human neuropathy $[50,76]$. Indeed, the components of this murine neurodegeneration are also observed in humans and the neuroprotection conferred by molecules on these models is also observed in humans $[18,68]$. This observation leads us to believe that the neuroprotection conferred by benztropine, which is currently indicated in Parkinson's disease in the United States, could be transposable to patients suffering from peripheral neuropathies. These very encouraging results for benztropine deserve to lead to a study in humans in order to be able to address a problematic with clinical relevance. The results of this clinical trial could lead to the exploration of benztropine as a potentially neuroprotective agent in other pathologies of the PNS.

\section{Additional files}

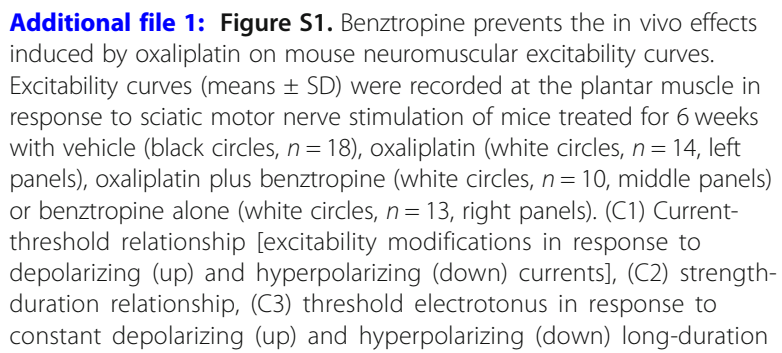

Additional file 1: Figure S1. Benztropine prevents the in vivo effects induced by oxaliplatin on mouse neuromuscular excitability curves. Excitability curves (means \pm SD) were recorded at the plantar muscle in response to sciatic motor nerve stimulation of mice treated for 6 weeks with vehicle (black circles, $n=18$ ), oxaliplatin (white circles, $n=14$, left panels), oxaliplatin plus benztropine (white circles, $n=10$, middle panels) or benztropine alone (white circles, $n=13$, right panels). (C1) Currentthreshold relationship [excitability modifications in response to depolarizing (up) and hyperpolarizing (down) currents], (C2) strengthduration relationship, (C3) threshold electrotonus in response to constant depolarizing (up) and hyperpolarizing (down) long-duration currents applied at sub-threshold intensity ( $\pm 40 \%)$, and (C4) recovery 
cycle. Note the absence of effect of oxaliplatin plus benztropine and benztropine alone, versus vehicle, on excitability waveforms. (TIF $1435 \mathrm{~kb}$ )

Additional file 2: Figure S2. Benztropine prevents the in vivo effects induced by diabetes on mouse neuromuscular excitability curves. Excitability curves (means \pm SD) were recorded at the plantar muscle in response to sciatic motor nerve stimulation of mice treated for 6 weeks with non-diabetic vehicle (black circles, $n=18$ ), diabetic vehicle (white circles, $n=16$, left panels), and diabetic benztropine (white circles, $n=14$, right panels). (C1) Current-threshold relationship [excitability modifications in response to depolarizing (up) and hyperpolarizing (down) currents], (C2) strength-duration relationship, (C3) threshold electrotonus in response to constant depolarizing (up) and hyperpolarizing (down) longduration currents applied at sub-threshold intensity ( $\pm 40 \%)$, and (C4) recovery cycle. Note the absence of effect of diabetic benztropine, versus non-diabetic vehicle, on excitability waveforms. (TIF $1006 \mathrm{~kb}$ )

Additional file 3: : Table S1. Benztropine prevents the in vivo effects induced by oxaliplatin and diabetes on mouse neuromuscular excitability variables. Variables (means $\pm \mathrm{SD}$ ) derived from excitability curves established from plantar muscle recordings in response to sciatic motor nerve stimulation of mice treated with vehicle $(n=18)$, oxaliplatin $(n=$ 14), oxaliplatin plus benztropine $(n=10)$, diabetic vehicle $(n=16)$, diabetic benztropine $(n=14)$ or benztropine alone $(n=13)$ for 6 weeks. (CO) Stimulus-response relationship, (C1) current-threshold relationship, (C2) strength-duration relationship, (C3) threshold electrotonus in response to constant depolarizing (TEd) and hyperpolarizing (TEh) long-duration currents applied at sub-threshold intensity $( \pm 40 \%)$, and (C4) recovery cycle. ${ }^{*} p<0.05,{ }^{*} p<0.01,{ }^{* * *} p<0.001$, and ${ }^{* * * *} p<0.0001$ versus vehicle (highlighted in grey). Note that, compared to vehicle; most if not all variables modified with oxaliplatin and diabetic vehicle remain unchanged with oxaliplatin plus benztropine, diabetic benztropine or benztropine alone. (TIF $593 \mathrm{~kb}$ )

Additional file 4: : Table S2. Comparison of morphometric parameters. Mean values \pm SD of morphometric parameters of single myelinated axons isolated from sciatic nerves of mice injected with vehicle, oxaliplatin, oxaliplatin plus benztropine or benztropine alone, for 6 weeks (137-206 axons from 4 different mice under each condition). ${ }^{*} P=0.011-0.049$, ${ }^{* *} P=$ 0.006 and ${ }^{* * *} P<0.0001$ versus vehicle (highlighted in grey). (TIF $155 \mathrm{~kb}$ )

\section{Acknowledgments}

The authors would like to thank Dr. Pierre Billuart for his expertise in perfusing the mice and kind advice. The authors are also very grateful to Dr. Thomas Guilbert for having created a macro allowing us to systematically measure the G-ratios on the sections of electron microscopy.

\section{Conflicts of interest}

The authors declare that they have no competing interests.

\section{Authors' contributions}

$\mathrm{OC}$ and $\mathrm{CN}$ carried out the celular, histological and animal experiments, participated in the drafted the manuscript. TCG realized the patch-clamp experiments, SC carried out the western blots. EB and TCG performed the electrophysiological explorations and confocal microscopy. AS carried out electronic microscopy. CC carried out the celular experiments, viability and ROS assays. CG performed the study of systemic inflammatory markers. NEBS, NK, BW, RC participated in the drafted the manuscript. OC and CN performed the statistical analysis. FB and CN conceived of the study and participated in its design and coordination. All authors read and approved the final manuscript.

\section{Competing interests}

Tânia Cristina Gonçalves was an employee of Sanofi (and a Sanofi hareholder via participation/profit-sharing) when these studies were conducted. All other co-authors declare no conflict of interest.

\section{Publisher's Note}

Springer Nature remains neutral with regard to jurisdictional claims in published maps and institutional affiliations.

\section{Author details}

"Department "Development, Reproduction and Cancer", Institut Cochin, Paris Descartes University, Sorbonne Paris City, INSERM U1016, Paris, France. ${ }^{2}$ Molecular engineering of proteins unit (SIMOPRO), CEA of Saclay, and Paris-Saclay Institute of Neuroscience (Neuro-PSI), UMR CNRS 9197, Paris-Saclay University, Gif-sur-Yvette, France. ${ }^{3}$ Sanofi R \& D, Integrated Drug Discovery - High Content Biology, Vitry-sur-Seine, France. ${ }^{4}$ Plateforme imagerie : microscopie électronique, Institut Cochin, INSERM U1016, Paris, France. ${ }^{5}$ Department of Immunology, Cochin Teaching Hospital, AP-HP, 27 , rue du faubourg Saint-Jacques, F75014 Paris, France. 'Service de diagnostic biologique automatisé, Cochin Teaching Hospital, Paris, France. ${ }^{7}$ Department of Gastroenterology, Cochin Teaching Hospital, Paris Descartes University, Paris, France.

Received: 14 November 2018 Accepted: 4 January 2019 Published online: 18 January 2019

\section{References}

1. Adelsberger H, Quasthoff S, Grosskreutz J, Lepier A, Eckel F, Lersch C (2000) The chemotherapeutic oxaliplatin alters voltage-gated $\mathrm{Na}(+)$ channel kinetics on rat sensory neurons. Eur J Pharmacol 406:25-32.

2. Agoston GE, Wu JH, Izenwasser S, George C, Katz J, Kline RH, Newman AH (1997) Novel N-substituted 3 alpha-[bis(4'-fluorophenyl)methoxy]tropane analogues: selective ligands for the dopamine transporter. J Med Chem 40: 4329-4339. https://doi.org/10.1021/jm970525a.

3. Alexandre J, Nicco C, Chéreau C, Laurent A, Weill B, Goldwasser F, Batteux F (2006) Improvement of the therapeutic index of anticancer drugs by the superoxide dismutase mimic mangafodipir. J Natl Cancer Inst 98:236-244. https://doi.org/10.1093/jnci/djj049.

4. André T, Boni C, Mounedji-Boudiaf L, Navarro M, Tabernero J, Hickish T, Topham C, Zaninelli M, Clingan P, Bridgewater J, Tabah-Fisch I, de Gramont A, Multicenter International Study of Oxaliplatin/5-Fluorouracil/Leucovorin in the Adjuvant Treatment of Colon Cancer (MOSAIC) Investigators (2004) Oxaliplatin, fluorouracil, and leucovorin as adjuvant treatment for colon cancer. N Engl J Med 350:2343-2351. https://doi.org/10.1056/ NEJMoa032709.

5. Bains JS, Shaw CA (1997) Neurodegenerative disorders in humans: the role of glutathione in oxidative stress-mediated neuronal death. Brain Res Brain Res Rev 25:335-358.

6. Bakogeorgos M, Georgoulias V (2017) Risk-reduction and treatment of chemotherapy-induced peripheral neuropathy. Expert Rev Anticancer Ther 17:1045-1060. https://doi.org/10.1080/14737140.2017.1374856.

7. Belrose JC, Xie Y-F, Gierszewski L, MacDonald JF, Jackson MF (2012) Loss of glutathione homeostasis associated with neuronal senescence facilitates TRPM2 channel activation in cultured hippocampal pyramidal neurons. Mol Brain 5:11. https://doi.org/10.1186/1756-6606-5-11.

8. Benoit E, Brienza S, Dubois JM (2006) Oxaliplatin, an anticancer agent that affects both $\mathrm{Na}+$ and $\mathrm{K}+$ channels in frog peripheral myelinated axons. Gen Physiol Biophys 25:263-276.

9. Brewer JR, Morrison G, Dolan ME, Fleming GF (2016) Chemotherapyinduced peripheral neuropathy: current status and progress. Gynecol Oncol 140:176-183. https://doi.org/10.1016/j.ygyno.2015.11.011

10. Brown DA, Passmore GM (2009) Neural KCNQ (Kv7) channels. Br J Pharmacol 156:1185-1195. https://doi.org/10.1111/j.1476-5381.2009.00111.x.

11. Calcutt NA, Smith DR, Frizzi K, Sabbir MG, Chowdhury SKR, Mixcoatl-Zecuatl T, Saleh A, Muttalib N, Van der Ploeg R, Ochoa J, Gopaul A, Tessler L, Wess J, Jolivalt CG, Fernyhough P (2017) Selective antagonism of muscarinic receptors is neuroprotective in peripheral neuropathy. J Clin Invest 127:608622. https://doi.org/10.1172/JCl88321.

12. Cantrell AR, Ma JY, Scheuer T, Catterall WA (1996) Muscarinic modulation of sodium current by activation of protein kinase $C$ in rat hippocampal neurons. Neuron 16:1019-1026.

13. Carozzi VA, Canta A, Chiorazzi A (2015) Chemotherapy-induced peripheral neuropathy: what do we know about mechanisms? Neurosci Lett 596:90107. https://doi.org/10.1016/j.neulet.2014.10.014

14. Cascinu S, Catalano V, Cordella L, Labianca R, Giordani P, Baldelli AM, Beretta GD, Ubiali E, Catalano G (2002) Neuroprotective effect of reduced glutathione on oxaliplatin-based chemotherapy in advanced colorectal cancer: a randomized, double-blind, placebo-controlled trial. J Clin Oncol Off J Am Soc Clin Oncol 20:3478-3483. https://doi.org/10.1200/JCO.2002.07.061. 
15. Cavaletti G, Alberti P, Marmiroli P (2011) Chemotherapy-induced peripheral neurotoxicity in the era of pharmacogenomics. Lancet Oncol 12:1151-1161. https://doi.org/10.1016/S1470-2045(11)70131-0.

16. Cerles $\mathrm{O}$, Benoit E, Chéreau C, Chouzenoux S, Morin F, Guillaumot M-A, Coriat R, Kavian N, Loussier T, Santulli P, Marcellin L, Saidu NEB, Weill B, Batteux F, Nicco C (2017) Niclosamide inhibits Oxaliplatin neurotoxicity while improving colorectal Cancer therapeutic response. Mol Cancer Ther 16:300-311. https://doi.org/10.1158/1535-7163.MCT-16-0326.

17. Cheng K, Shang AC, Drachenberg CB, Zhan M, Raufman J-P (2017) Differential expression of $\mathrm{M} 3$ muscarinic receptors in progressive colon neoplasia and metastasis. Oncotarget 8:21106-21114. https://doi.org/10. 18632/oncotarget.15500.

18. Coriat R, Alexandre J, Nicco C, Quinquis L, Benoit E, Chéreau C, Lemaréchal H, Mir O, Borderie D, Tréluyer J-M, Weill B, Coste J, Goldwasser F, Batteux F (2014) Treatment of oxaliplatin-induced peripheral neuropathy by intravenous mangafodipir. J Clin Invest 124:262-272. https://doi.org/10.1172/JCl68730.

19. Cui J, Hollmén M, Li L, Chen Y, Proulx ST, Reker D, Schneider G, Detmar M (2016) New use of an old drug: inhibition of breast cancer stem cells by benztropine mesylate. Oncotarget 8:1007-1022. https://doi.org/10.18632/ oncotarget.13537.

20. Cunha T (2005) A cascade of cytokines mediates mechanical inflammatory hypernociception in mice. - PubMed - NCBI. Proc Natl Acad Sci 102(5):17551760.

21. de Gramont A, Figer A, Seymour M, Homerin M, Hmissi A, Cassidy J, Boni C, Cortes-Funes H, Cervantes A, Freyer G, Papamichael D, Le Bail N, Louvet C, Hendler D, de Braud F, Wilson C, Morvan F, Bonetti A (2000) Leucovorin and fluorouracil with or without oxaliplatin as first-line treatment in advanced colorectal cancer. J Clin Oncol Off J Am Soc Clin Oncol 18:2938-2947. https://doi.org/10.1200/JCO.2000.18.16.2938.

22. Deshmukh VA, Tardif V, Lyssiotis CA, Green CC, Kerman B, Kim HJ, Padmanabhan K, Swoboda JG, Ahmad I, Kondo T, Gage FH, Theofilopoulos AN, Lawson BR, Schultz PG, Lairson LL (2013) A regenerative approach to the treatment of multiple sclerosis. Nature 502:327-332. https://doi.org/10. 1038/nature12647.

23. Deuis JR, Zimmermann K, Romanovsky AA, Possani LD, Cabot PJ, Lewis RJ, Vetter I (2013) An animal model of oxaliplatin-induced cold allodynia reveals a crucial role for Nav1.6 in peripheral pain pathways. Pain 154:17491757. https://doi.org/10.1016/j.pain.2013.05.032.

24. Doughty CT, Seyedsadjadi R (2018) Approach to peripheral neuropathy for the primary care clinician. Am J Med. https://doi.org/10.1016/j.amjmed.2017. 12.042.

25. Feldman EL, Bennett DLH, Nave K-A, Jensen TS (2017) New horizons in diabetic neuropathy: mechanisms, bioenergetics, and pain. Neuron 93:12961313. https://doi.org/10.1016/j.neuron.2017.02.005.

26. Felton J, Hu S, Raufman J-P (2018) Targeting M3 muscarinic receptors for Colon Cancer therapy. Curr Mol Pharmacol. https://doi.org/10.2174/ 1874467211666180119115828.

27. Fields RD, Dutta DJ, Belgrad J, Robnett M (2017) Cholinergic signaling in myelination. Glia 65:687-698. https://doi.org/10.1002/glia.23101.

28. Flatters SJL, Bennett GJ (2006) Studies of peripheral sensory nerves in paclitaxel-induced painful peripheral neuropathy: evidence for mitochondrial dysfunction. Pain 122:245-257. https://doi.org/10.1016/j.pain. 2006.01.037.

29. Fujii T (2017) Expression and Function of the Cholinergic System in Immune Cells - PubMed - NCBI. Front Immunol 8:1085

30. Goebbels S, Oltrogge JH, Kemper R, Heilmann I, Bormuth I, Wolfer S, Wichert SP, Mobius W, Liu X, Lappe-Siefke C, Rossner MJ, Groszer M, Suter U, Frahm J, Boretius S, Nave K-A (2010) Elevated phosphatidylinositol 3,4,5trisphosphate in glia triggers cell-autonomous membrane wrapping and myelination. J Neurosci 30:8953-8964. https://doi.org/10.1523/JNEUROSCl. 0219-10.2010

31. Gonçalves NP, Vægter CB, Andersen H, Østergaard L, Calcutt NA, Jensen TS (2017) Schwann cell interactions with axons and microvessels in diabetic neuropathy. Nat Rev Neurol 13:135-147. https://doi.org/10.1038/nrneurol. 2016.201.

32. Gonçalves NP, Vægter CB, Pallesen LT (2018) Peripheral glial cells in the development of diabetic neuropathy. Front Neurol 9. https://doi.org/10. 3389/fneur.2018.00268.

33. González-Reyes S, Guzmán-Beltrán S, Medina-Campos ON, Pedraza-Chaverri $J$ (2013) Curcumin pretreatment induces Nrf2 and an antioxidant response and prevents hemin-induced toxicity in primary cultures of cerebellar granule neurons of rats. Oxidative Med Cell Longev 2013:801418. https:// doi.org/10.1155/2013/801418.

34. Grisold W, Cavaletti G, Windebank AJ (2012) Peripheral neuropathies from chemotherapeutics and targeted agents: diagnosis, treatment, and prevention. Neuro-Oncology 14(Suppl 4):iv45-iv54. https://doi.org/10.1093/ neuonc/nos203.

35. Hache G, Guiard BP, Nguyen TH, Quesseveur G, Gardier AM, Peters D, Munro G, Coudoré F (2015) Antinociceptive activity of the new triple reuptake inhibitor NS18283 in a mouse model of chemotherapy-induced neuropathic pain. Eur J Pain 19:322-333. https://doi.org/10.1002/ejp.550.

36. Heinen A, Lehmann HC, Küry P (2013) Negative regulators of schwann cell differentiation-novel targets for peripheral nerve therapies? J Clin Immunol 33(Suppl 1):S18-S26. https://doi.org/10.1007/s10875-012-9786-9.

37. Imai S, Koyanagi M, Azimi Z, Nakazato Y, Matsumoto M, Ogihara T, Yonezawa A, Omura T, Nakagawa S, Wakatsuki S, Araki T, Kaneko S, Nakagawa T, Matsubara K (2017) Taxanes and platinum derivatives impair Schwann cells via distinct mechanisms. Sci Rep 7:5947. https://doi.org/10. 1038/s41598-017-05784-1.

38. labal A, George TJ (2017) Randomized clinical trials in Colon and Rectal Cancer. Surg Oncol Clin N Am 26:689-704. https://doi.org/10.1016/j.soc. 2017.05.008.

39. Jack MM, Ryals JM, Wright DE (2012) Protection from diabetes-induced peripheral sensory neuropathy--a role for elevated glyoxalase I? Exp Neurol 234:62-69. https://doi.org/10.1016/j.expneurol.2011.12.015.

40. Kagiava A, Tsingotjidou A, Emmanouilides C, Theophilidis G (2008) The effects of oxaliplatin, an anticancer drug, on potassium channels of the peripheral myelinated nerve fibres of the adult rat. Neurotoxicology 29: 1100-1106. https://doi.org/10.1016/j.neuro.2008.09.005.

41. Kamei N, Tobe K, Suzuki R, Ohsugi M, Watanabe T, Kubota N, OhtsukaKowatari N, Kumagai K, Sakamoto K, Kobayashi M, Yamauchi T, Ueki K, Oishi Y, Nishimura S, Manabe I, Hashimoto H, Ohnishi Y, Ogata H, Tokuyama K, Tsunoda M, Ide T, Murakami K, Nagai R, Kadowaki T (2006) Overexpression of monocyte chemoattractant protein-1 in adipose tissues causes macrophage recruitment and insulin resistance. J Biol Chem 281:2660226614. https://doi.org/10.1074/jbc.M601284200.

42. Kellogg AP, Wiggin TD, Larkin DD, Hayes JM, Stevens MJ, Pop-Busui R (2007) Protective effects of cyclooxygenase-2 gene inactivation against peripheral nerve dysfunction and intraepidermal nerve fiber loss in experimental diabetes. Diabetes 56:2997-3005. https://doi.org/10.2337/db07-0740

43. Keswani SC, Polley M, Pardo CA, Griffin JW, MCArthur JC, Hoke A (2003) Schwann cell chemokine receptors mediate HIV-1 gp120 toxicity to sensory neurons. Ann Neurol 54:287-296. https://doi.org/10.1002/ana.10645.

44. Khalilzadeh E, Azarpey F, Hazrati R, Vafaei Saiah G (2018) Evaluation of different classes of histamine $\mathrm{H} 1$ and $\mathrm{H} 2$ receptor antagonist effects on neuropathic nociceptive behavior following tibial nerve transection in rats. Eur J Pharmacol 834:221-229. https://doi.org/10.1016/j.ejphar.2018.07.011.

45. Kiernan MC, Burke D, Andersen KV, Bostock H (2000) Multiple measures of axonal excitability: a new approach in clinical testing. Muscle Nerve 23:399-409.

46. Krishnan AV, Lin CS-Y, Park SB, Kiernan MC (2008) Assessment of nerve excitability in toxic and metabolic neuropathies. J Peripher Nerv Syst JPNS 13:7-26. https://doi.org/10.1111/j.1529-8027.2008.00155.x.

47. Laedermann CJ, Abriel H, Decosterd I (2015) Post-translational modifications of voltage-gated sodium channels in chronic pain syndromes. Front Pharmacol 6. https://doi.org/10.3389/fphar.2015.00263.

48. Lang PM, Fleckenstein J, Passmore GM, Brown DA, Grafe P (2008) Retigabine reduces the excitability of unmyelinated peripheral human axons. Neuropharmacology 54:1271-1278. https://doi.org/10.1016/j.neuropharm. 2008.04.006

49. Laurent A, Nicco C, Chéreau C, Goulvestre C, Alexandre J, Alves A, Lévy E, Goldwasser F, Panis Y, Soubrane O, Weill B, Batteux F (2005) Controlling tumor growth by modulating endogenous production of reactive oxygen species. Cancer Res 65:948-956.

50. Lehky TJ, Leonard GD, Wilson RH, Grem JL, Floeter MK (2004) Oxaliplatininduced neurotoxicity: acute hyperexcitability and chronic neuropathy. Muscle Nerve 29:387-392. https://doi.org/10.1002/mus.10559.

51. Lehmann HC, Höke A (2010) Schwann cells as a therapeutic target for peripheral neuropathies. CNS Neurol Disord Drug Targets 9:801-806.

52. Liu Z, Jin Y-Q, Chen L, Wang Y, Yang X, Cheng J, Wu W, Qi Z, Shen Z (2015) Specific marker expression and cell state of Schwann cells during culture in vitro. PLoS One 10:e0123278. https://doi.org/10.1371/journal.pone.0123278. 
53. Lopes LCG, Galhardoni R, Silva V, Jorge FMH, Yeng LT, Callegaro D, Chadi G, Teixeira MJ, Ciampi de Andrade D (2018) Beyond weakness: characterization of pain, sensory profile and conditioned pain modulation in patients with motor neuron disease: a controlled study. Eur J Pain Lond Engl 22:72-83. https://doi.org/10.1002/ejp.1091.

54. Loprinzi CL, Qin R, Dakhil SR, Fehrenbacher L, Flynn KA, Atherton P, Seisler D, Qamar R, Lewis GC, Grothey A (2014) Phase III randomized, placebo-controlled, double-blind study of intravenous calcium and magnesium to prevent oxaliplatin-induced sensory neurotoxicity (N08CB/Alliance). J Clin Oncol Off J Am Soc Clin Oncol 32:997-1005. https://doi.org/10.1200/JCO.2013.52.0536.

55. Loreti S, Vilaró MT, Visentin S, Rees H, Levey Al, Tata AM (2006) Rat Schwann cells express M1-M4 muscarinic receptor subtypes. J Neurosci Res 84:97105. https://doi.org/10.1002/jnr.20874.

56. Mangelus M, Kroyter A, Galron R, Sokolovsky M (2001) Reactive oxygen species regulate signaling pathways induced by $\mathrm{M} 1$ muscarinic receptors in PC12M1 cells. J Neurochem 76:1701-1711.

57. Marchand F, Perretti M, McMahon SB (2005) Role of the immune system in chronic pain. Nat Rev Neurosci 6:521-532. https://doi.org/10.1038/nrn1700.

58. McKearney JW (1982) Stimulant actions of histamine $\mathrm{H} 1$ antagonists on operant behavior in the squirrel monkey. Psychopharmacology 77:156-158.

59. Melemedjian OK, Tillu DV, Moy JK, Asiedu MN, Mandell EK, Ghosh S, Dussor G, Price TJ (2014) Local translation and retrograde axonal transport of CREB regulates IL-6-induced nociceptive plasticity. Mol Pain 10:45. https://doi.org/ 10.1186/1744-8069-10-45

60. Mendell J (2003) Painful sensory neuropathy. N Engl J Med 348(13). https:// doi.org/10.1056/NEJMcp022282.

61. Miraucourt LS, Moisset X, Dallel R, Voisin DL (2009) Glycine inhibitory dysfunction induces a selectively dynamic, morphine-resistant, and neurokinin 1 receptor- independent mechanical allodynia. J Neurosci 29: 2519-2527. https://doi.org/10.1523/JNEUROSCl.3923-08.2009.

62. Morales M-C, Pérez-Yarza G, Nieto-Rementeria N, Boyano M-D, Jangi M, Atencia R, Asumendi A (2005) Intracellular glutathione levels determine cell sensitivity to apoptosis induced by the antineoplasic agent $\mathrm{N}$-(4hydroxyphenyl) retinamide. Anticancer Res 25:1945-1951.

63. Park B, Kim K, Rhee D, Pyo S (2012) The apoptotic effect of allicin in MCF-7 human breast cancer cells: role for ATF3. FASEB J 26:lb367-lb367.

64. Passmore G, Brown D (2007) Effects of M-channel mod-ulators on peripheral excitability inrat hairy skin. Soc Neurosci Abstr 681:8.

65. Peters CM, Jimenez-Andrade JM, Jonas BM, Sevcik MA, Koewler NJ, Ghilardi JR, Wong GY, Mantyh PW (2007) Intravenous paclitaxel administration in the rat induces a peripheral sensory neuropathy characterized by macrophage infiltration and injury to sensory neurons and their supporting cells. Exp Neurol 203:42-54. https://doi.org/10.1016/j.expneurol.2006.07.022.

66. Pulvers JN, Marx G (2017) Factors associated with the development and severity of oxaliplatin-induced peripheral neuropathy: a systematic review. Asia Pac J Clin Oncol. https://doi.org/10.1111/ajco.12694.

67. Rawlins FA, Villegas J (1978) Autoradiographic localization of acetylcholine receptors in the Schwann cell membrane of the squid nerve fiber. J Cell Biol 77:371-376.

68. Renn CL, Carozzi VA, Rhee P, Gallop D, Dorsey SG, Cavaletti G (2011) Multimodal assessment of painful peripheral neuropathy induced by chronic oxaliplatin-based chemotherapy in mice. Mol Pain 7:29. https://doi. org/10.1186/1744-8069-7-29.

69. Sagara M, Satoh J, Wada R, Yagihashi S, Takahashi K, Fukuzawa M, Muto G, Muto Y, Toyota T (1996) Inhibition of development of peripheral neuropathy in streptozotocin-induced diabetic rats with $\mathrm{N}$-acetylcysteine. Diabetologia 39:263-269.

70. Schlumberger S, Kristan KČ, Ota K, Frangež R, Molgó J, Sepčić K, Benoit E, Maček P (2014) Permeability characteristics of cell-membrane pores induced by ostreolysin a/pleurotolysin B, binary pore-forming proteins from the oyster mushroom. FEBS Lett 588:35-40. https://doi.org/10.1016/j.febslet. 2013.10.038.

71. Scholz J, Woolf CJ (2007) The neuropathic pain triad: neurons, immune cells and glia. Nat Neurosci 10:1361-1368. https://doi.org/10.1038/nn1992.

72. Seretny M, Currie GL, Sena ES, Ramnarine S, Grant R, MacLeod MR, Colvin LA, Fallon M (2014) Incidence, prevalence, and predictors of chemotherapyinduced peripheral neuropathy: a systematic review and meta-analysis. Pain 155:2461-2470. https://doi.org/10.1016/j.pain.2014.09.020

73. Shi X, Chen Y, Nadeem L, Xu G (2013) Beneficial effect of TNF-a inhibition on diabetic peripheral neuropathy. J Neuroinflammation 10:69. https://doi. org/10.1186/1742-2094-10-69.
74. Sima AAF, Zhang W (2014) Mechanisms of diabetic neuropathy: axon dysfunction. Handb Clin Neurol 126:429-442. https://doi.org/10.1016/B9780-444-53480-4.00031-X.

75. Sittl R, Carr RW, Schwarz JR, Grafe P (2010) The Kv7 potassium channel activator flupirtine affects clinical excitability parameters of myelinated axons in isolated rat sural nerve. J Peripher Nerv Syst JPNS 15:63-72. https:// doi.org/10.1111/j.1529-8027.2010.00253.x.

76. Sittl R, Lampert A, Huth T, Schuy ET, Link AS, Fleckenstein J, Alzheimer C, Grafe P, Carr RW (2012) Anticancer drug oxaliplatin induces acute coolingaggravated neuropathy via sodium channel subtype $\mathrm{Na}(\mathrm{V}) 1.6$-resurgent and persistent current. Proc Natl Acad Sci U S A 109:6704-6709. https://doi.org/ 10.1073/pnas.1118058109.

77. Spindel ER (2012) Muscarinic receptor agonists and antagonists: effects on Cancer. Handb Exp Pharmacol:451-468. https://doi.org/10.1007/978-3-64223274-9_19.

78. Starkweather A (2010) Increased interleukin-6 activity associated with painfu chemotherapy-induced peripheral neuropathy in women after breast cancer treatment. Nurs Res Pract 2010:281531. https://doi.org/10.1155/2010/ 281531.

79. Ta LE, Low PA, Windebank AJ (2009) Mice with cisplatin and oxaliplatininduced painful neuropathy develop distinct early responses to thermal stimuli. Mol Pain 5:9. https://doi.org/10.1186/1744-8069-5-9.

80. Trachootham D, Alexandre J, Huang P (2009) Targeting cancer cells by ROSmediated mechanisms: a radical therapeutic approach? Nat Rev Drug Discov 8:579-591. https://doi.org/10.1038/nrd2803.

81. Ulugol A, Oltulu C, Gunduz O, Citak C, Carrara R, Shaqaqi MR, Sanchez AM, Dogrul A (2012) 5-HT7 receptor activation attenuates thermal hyperalgesia in streptozocin-induced diabetic mice. Pharmacol Biochem Behav 102:344348. https://doi.org/10.1016/j.pbb.2012.05.006

82. Urrunaga NH, Jadeja RN, Rachakonda V, Ahmad D, McLean LP, Cheng K, Shah V, Twaddell WS, Raufman J-P, Khurana S (2015) M1 muscarinic receptors modify oxidative stress response to acetaminophen-induced acute liver injury. Free Radic Biol Med 78:66-81. https://doi.org/10.1016/j. freeradbiomed.2014.09.032

83. Vazquez E, Kahlenbach J, Segond von Banchet G, König C, Schaible H-G, Ebersberger A (2012) Spinal interleukin-6 is an amplifier of arthritic pain in the rat. Arthritis Rheum 64:2233-2242. https://doi.org/10.1002/art.34384.

84. Verdiyan EE, Allakhverdiev ES, Maksimov GV (2016) Study of the peripheral nerve fibers myelin structure changes during activation of Schwann cell acetylcholine receptors. PLoS One 11:e0158083. https://doi.org/10.1371/ journal.pone.0158083.

85. Verstappen CCP, Heimans JJ, Hoekman K, Postma TJ (2003) Neurotoxic complications of chemotherapy in patients with cancer: clinical signs and optimal management. Drugs 63:1549-1563.

86. Vinik Al, Casellini C, Névoret ML. Alternative Quantitative Tools in the Assessment of DiabeticPeripheral and Autonomic Neuropathy. Int Rev Neurobiol. 2016;127:235-85. https://www-ncbi-nlm-nih-gov.frodon.univparis5.fr/pubmed/?term=Alternative+Quantitative+Tools+in+the +Assessment+of+Diabetic+Peripheral+and+Autonomic+Neuropathy.

87. Wagner AD, Syn NL, Moehler M, Grothe W, Yong WP, Tai B-C, Ho J, Unverzagt S (2017) Chemotherapy for advanced gastric cancer. Cochrane Database Syst Rev 8:CD004064. https://doi.org/10.1002/14651858.CD004064.pub4.

88. Watson JC, Dyck PJB (2015) Peripheral neuropathy: a practical approach to diagnosis and symptom management. Mayo Clin Proc 90:940-951. https:// doi.org/10.1016/j.mayocp.2015.05.004.

89. Webster RG, Brain KL, Wilson RH, Grem JL, Vincent A (2005) Oxaliplatin induces hyperexcitability at motor and autonomic neuromuscular junctions through effects on voltage-gated sodium channels. Br J Pharmacol 146: 1027-1039. https://doi.org/10.1038/sj.bjp.0706407.

90. Wu D-F, Chandra D, McMahon T, Wang D, Dadgar J, Kharazia VN, Liang Y-J, Waxman SG, Dib-Hajj SD, Messing RO (2012) PKC $\varepsilon$ phosphorylation of the sodium channel NaV1.8 increases channel function and produces mechanical hyperalgesia in mice. J Clin Invest 122:1306-1315. https://doi. org/10.1172/JCl61934.

91. Yu H, Xia H, Tang Q, Xu H, Wei G, Chen Y, Dai X, Gong Q, Bi F (2017) Acetylcholine acts through M3 muscarinic receptor to activate the EGFR signaling and promotes gastric cancer cell proliferation. Sci Rep 7:40802. https://doi.org/10.1038/srep40802. 